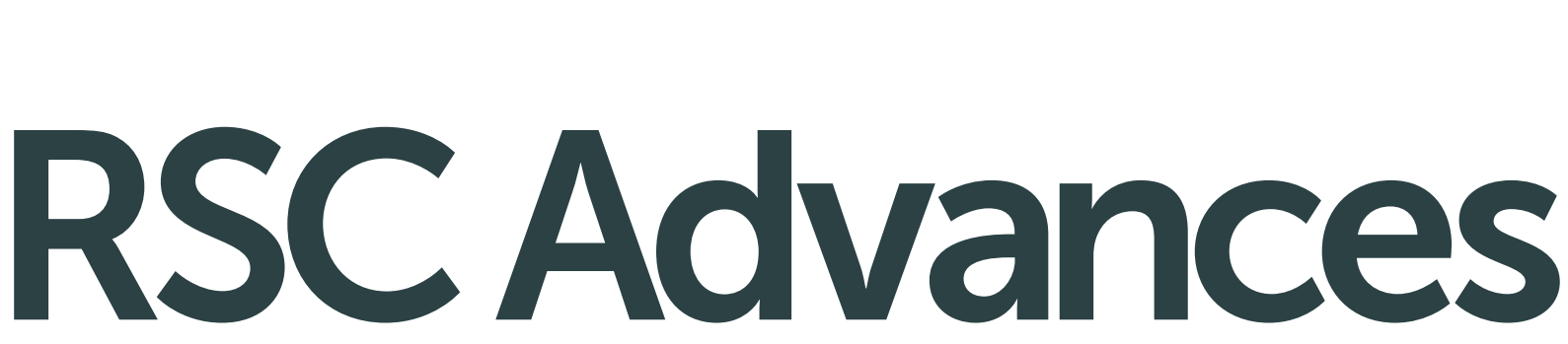

This article can be cited before page numbers have been issued, to do this please use: S. C. Nunes, C. B. Ferreira, R. Ferreira, L. A. D. Carlos, M. Ferro, J. Mano, P. Almeida and V. de Zea Bermudez, RSC Adv.,

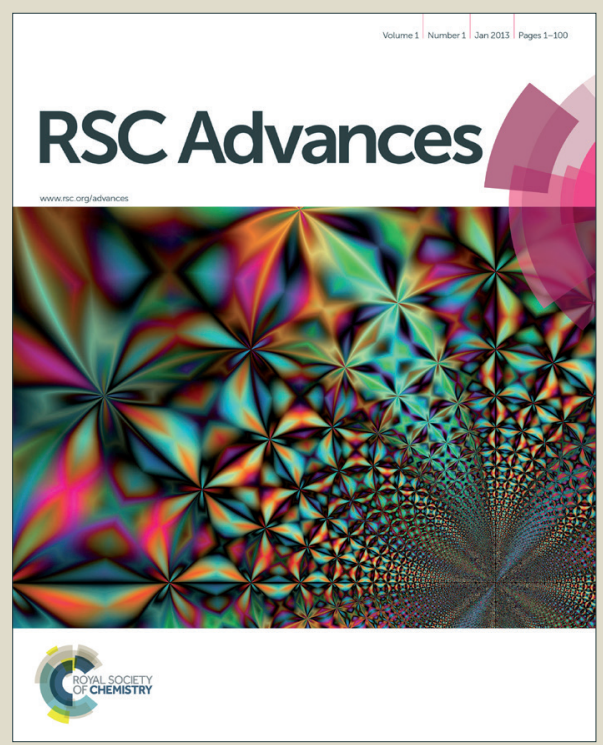

This is an Accepted Manuscript, which has been through the Royal Society of Chemistry peer review process and has been accepted for publication.

Accepted Manuscripts are published online shortly after acceptance, before technical editing, formatting and proof reading. Using this free service, authors can make their results available to the community, in citable form, before we publish the edited article. This Accepted Manuscript will be replaced by the edited, formatted and paginated article as soon as this is available.

You can find more information about Accepted Manuscripts in the Information for Authors.

Please note that technical editing may introduce minor changes to the text and/or graphics, which may alter content. The journal's standard Terms \& Conditions and the Ethical guidelines still apply. In no event shall the Royal Society of Chemistry be held responsible for any errors or omissions in this Accepted Manuscript or any consequences arising from the use of any information it contains. 


\title{
Fractality and metastability of a complex amide cross-linked dipodal alkyl/siloxane hybrid
}

\author{
S. C. Nunes ${ }^{\mathrm{a}, \mathrm{b}^{*}}$, C. B. Ferreira ${ }^{\mathrm{b}}$, R. A. S. Ferreira ${ }^{\mathrm{c}}$, L. D. Carlos ${ }^{\mathrm{c}}$, M. C. Ferro ${ }^{\mathrm{d}}$, J. F. Mano ${ }^{\mathrm{e}, \mathrm{f}}$, P. Almeida , $^{\mathrm{a}}$, \\ ${ }_{5}$ Verónica de Zea Bermudez ${ }^{\mathrm{b}, \mathbf{g}^{*}}$
}

A novel room-temperature white light emitter amide-cross linked alkyl/siloxane hybrid material (amidosil A) was produced by selforganization through the rational design of the precursor. This hybrid displays a highly complex hierarchical architecture composed of two lamellar bilayer structures, the relative spatial arrangement of which yields a multiplicity of ordered nanodomains with variable 10 shapes and sizes, some of them persisting at the microscale. Macroscopically A was obtained as clusters of hydrophobic hemispherical and spherical micro-objects exhibiting a lettuce coral-like pattern, which represent unprecedented pieces of evidence illustrating the principles of self-similarity and demonstrating that the time scale of biomimetic morphogenesis in this non-bridged silsesquioxane is similar to that in biological systems. Heating metastable $\mathbf{A}$ above the order/disorder phase transition acted as an external quake driving the material to another metastable state, which has persisted for more than 12 months, and was manifested as a marked change of all the

15 macroscopic properties. The occurrence of the self-organization process operating on A, instead of a self-directed assembly, is primarily associated with the formation/rupture of hydrogen bonds, therefore supporting that these interactions are critical factors dictating on what side of the self-assembly/self-organization boundary will a non-bridged silsesquioxane system evolve.

Received (in XXX, XXX) Xth XXXXXXXXX 20XX, Accepted Xth XXXXXXXXX 20XX

${ }_{20}$ DOI: $10.1039 / \mathbf{b 0 0 0 0 0 0 x}$

\section{Introduction}

In the last few years biomimetic strategies have been extensively adopted by the community of materials science with 25 the goal of designing innovative materials exhibiting the extraordinary features offered by materials in Nature: high sophistication, intricate architectures and patterns, hybrid synergy, miniaturization, integration and adaptability. ${ }^{1}$ Materials from the natural world are known to be complex systems ${ }^{2,3}$ which 30 provide plenty of inspiring examples of hierarchical arrangement, ${ }^{2,4,5}$ self-similarity growth6 and emergent phenomena. ${ }^{7}$

Currently self-assembly stands as one of the few available practical approaches for organizing matter on large scales and the 35 key driving force in the integration of natural and synthetic materials ${ }^{8-13}$ It is not straightforward to define "self-assembly". While this term has been often used imprecisely, some authors prefer to use the term "self-organization" instead. Indeed selfassembly and self-organization are concepts that have been 40 employed indiscriminately by numerous scientific disciplines, including biology, chemistry and physics, with different highlights in each. Although both terms refer to mechanisms generating collective order from small-scale interactions, they may be distinguished on the basis of thermodynamic arguments. ${ }^{14}$

${ }_{45}$ Self-assembly concerns non-dissipative structural order on a macroscopic level owing to collective interactions between multiple components (often microscopic) which retain their character when integrated in the self-assembled structure. ${ }^{14,15}$ Self-assembly is a spontaneous process, since the energy of the 50 components is higher than that of the self-assembled structure, which is in static equilibrium and remains as such in the absence of energy input. In contrast, self-organization regards dissipative non-equilibrium order at macroscopic levels, as a result of collective, non-linear interactions between multiple microscopic 55 components. ${ }^{14,15}$ In this case order is promoted by the interchange between intrinsic and extrinsic factors, but collapses upon cessation of the energy input.

Following the general trend driving materials science research, in recent years the community of organic/inorganic 60 hybrids shifted its interests to the creation of organized systems exhibiting multi-scale order. ${ }^{16,17}$ To achieve this challenging goal researchers have combined classical sol-gel reactions ${ }^{18}$ with selfassembly routes which in general require the presence of a structure directing agent (template) ${ }^{.11}$ 
We have been particularly interested in the development of ordered hybrid materials by means of self-directed assembly, ${ }^{19}$ a self-assembly process governed by weak interactions (e.g., van der Waals, hydrogen bonding, $\pi-\pi$ ) in which the growing 5 supramolecular architecture plays itself the role of internal template. Most of the hybrids produced in the framework of this approach have been bridged silsesquioxanes. ${ }^{19-21}$ The early reports of ordered non-bridged silsesquioxanes lacking any crosslinks regarded lamellar materials derived from $\mathrm{n}$ 10 alkyltriethoxysilanes ${ }^{22}$ and n-alkyltrichlorosilanes. ${ }^{23}$ Nanostructured hybrids with lamellar or two-dimensional (2D) hexagonal structures ${ }^{24,25}$ were obtained later from precursors incorporating pendant alkyl chains and branched trimethoxysilyl groups. Three-dimensional mesostructured mesophases were later 15 developed from a branched heptasiloxane precursor. ${ }^{26}$ The first organized non-bridged silsesquioxane synthesized via selfdirected assembly and incorporating a cross-link was a highly organized hierarchically structured lamellar bilayer hybrid obtained by our group from a n20 hexadecanoylamidepropyltriethoxysilane precursor. $^{27}$ This material, called mono-amidosil and noted as m-A(14) (where 14 is the number of $\mathrm{CH} 2$ repeat units), represents the first example of a photoluminescent bilayered suprastructure displaying nanoscopic sensitivity. In m-A(14) self-assembly is driven by 25 intermolecular hydrogen bonding between amide groups, van der Waals interactions between all-trans alkyl chains assuming a partially interdigitated packing mode, and an entropic term related to the phase separation between the alkyl chains and the siloxane nanodomains. The operating self-assembly driving 30 forces determine the emergence of a thermally-actuated optical memory effect (hysteretic behaviour of the emission energy) activated by the reversible order/disorder phase transition of the alkyl chains with onset at $92{ }^{\circ} \mathrm{C}$. The recovery of the emission energy follows a logarithmic time dependence, demonstrating 35 hierarchically constrained dynamics without any characteristic microscopic time.

To generate other bilayer suprastructures displaying similar thermally activated photoluminescence memory effects and especially to lower the hysteretic range and thus yield materials 40 mechanically more resistant to consecutive heating/cooling cycles, several methodologies were subsequently adopted: (1) Changing the nature of the cross-link: ${ }^{28}$ (2) Incorporating mono-, di- and trivalent salts; ${ }^{29,30}$ (3) Adding dye compounds (monomethinecyanines ${ }^{31}$ and Rhodamines ${ }^{32}$ ). The replacement of 45 the amide group by an urethane group resulted in a series of lamellar bilayer hierarchically structured analogues named monourethanesils (noted as $\mathrm{m}-\mathrm{Ut}(\mathrm{Y})$-ac with $\mathrm{Y}=14,16$ and 22, where $\mathrm{Y}$ is the number of $\mathrm{CH}_{2}$ repeat units and ac represents acid catalysis) with intricate morphologies that resemble cabbage ${ }_{50}$ leaves or the desert rose. ${ }^{28}$ The order/disorder phase transitions of $\mathrm{m}$-Ut(14)-ac and $\mathrm{m}$-Ut(16)-ac occur at lower temperatures than in that of $\mathrm{m}-\mathrm{A}(14)$ and, although reversible, they are timeindependent. We also succeeded in decreasing the order/disorder phase transition temperature through the addition of $\mathrm{K}^{+}, \mathrm{Mg}^{2+}$ and ${ }_{55} \mathrm{Eu}^{3+}$ ions incorporated as triflate salts. ${ }^{30}$ In these materials, at moderate salt concentration, the original lamellar structure of $\mathrm{m}$ $\mathrm{A}(14)$ coexists with a new lamellar phase with lower interlamellar distance. The morphology of the resulting materials mimics cabbage leaves, foliated schist and sea sponges, ${ }_{60}$ respectively. The structural changes undergone by the alkyl chains of selected $\mathrm{K}^{+}-, \mathrm{Mg}^{2+}$ - and $\mathrm{Eu}^{3+}$-containing monoamidosils in a heating/cooling cycle are also reversible and timeindependent. Interestingly, these materials exhibit two distinct hysteresis domains, one associated with the order/disorder phase ${ }_{65}$ transition of the original lamellar bilayer structure of m- $\mathrm{A}(14)$ and the second one associated with the order/disorder phase transition of the new lamellar bilayer structure which is formed in the presence of the guest salts.

In the present work the strategy adopted relied on the 70 introduction of a ramification in the pendant alkyl chain of the precursor of $\mathrm{m}-\mathrm{A}(14)$. The new dipodal alkoxysilane molecule synthesized (P) includes a secondary amide group and a tertiary amide group both linked to pendant alkyl chains with 13 carbon atoms (Scheme 1). With this change in the precursor architecture 75 we pursued a more ambitious goal than in previous studies. Here we hoped to be able to capture for the first time intermediate steps of the morphogenesis process in a non-bridged silsesquioxane, by slowing down considerably the crystallization rate, forcing the resulting material to be far from equilibrium and 80 making it evolve via self-organization instead of self-assembly.

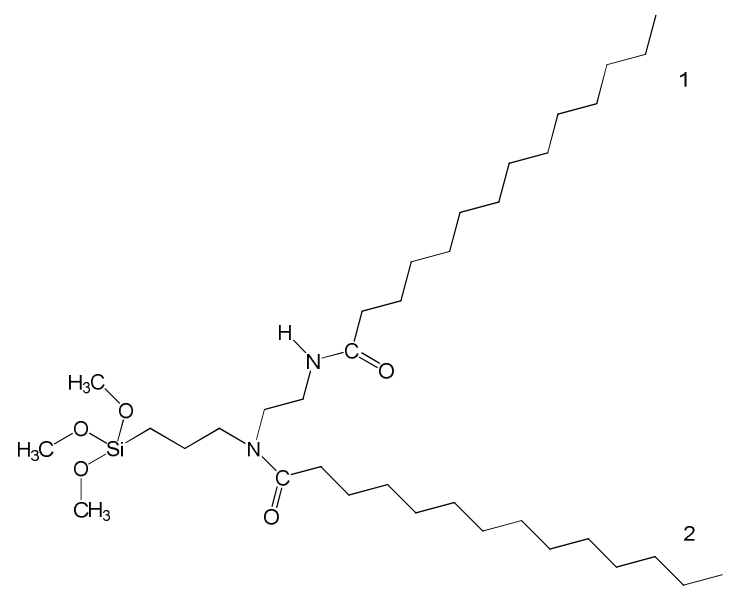

Scheme 1. Chemical structure of the hybrid precursor $\mathbf{P}$. 85

\section{Experimental Section}

2.1 Materials and synthetic procedure:

Synthesis of P. A volume of $1 \mathrm{~mL}(3.790 \mathrm{mmol})$ of myristoyl 90 chloride $\left(\mathrm{ClC}(=\mathrm{O})-\left(\mathrm{CH}_{2}\right)_{12} \mathrm{CH}_{3}, \mathrm{MC}\right.$, Aldrich $)$ was added to a solution prepared through the addition of $0.500 \mathrm{~mL}(1.849 \mathrm{mmol})$ of $\mathrm{N}$-[3-(trimethoxysilyl)propyl]ethylenediamine $\left(\left(\mathrm{CH}_{3} \mathrm{O}\right)_{3} \mathrm{Si}\left(\mathrm{CH}_{2}\right)_{3} \mathrm{NH}\left(\mathrm{CH}_{2}\right)_{2} \mathrm{NH}_{2}\right.$, TMSPED, Aldrich) to a $20 \mathrm{~mL}$ tetrahydrofuran (THF, Merck) solution containing $60 \mu \mathrm{L}(0.740$ $95 \mathrm{mmol}$ ) of pyridine (py, Aldrich, 99.8\%) and $0.944 \mathrm{~g}(4.440$ mmol)) of Amberlyst A-21 Ion-Exchange Resin (4.7 meq/g, Aldrich) which was washed with THF and stored in an oven at 80 ${ }^{\circ} \mathrm{C}$ prior to being used. The molar ratio TMSPED:MC:py:resin was $1: 2.4: 0.4: 2.4$. The resulting mixture was sealed and stirred at 100 room temperature during one day. The intensity of the FT-IR band attributed to the stretching vibration of the $\mathrm{C}=\mathrm{O}$ group of 
the chloride acid, at $1800 \mathrm{~cm}^{-1}$ was progressively reduced, until it disappeared upon completion of the reaction. In parallel, a series of new bands, associated with the vibrations of the amide group, appeared in the $1760-1530 \mathrm{~cm}^{-1}$ region. The solution was filtrated 5 and the solvent evaporated. The solution was filtrated and the solvent evaporated. The final material, obtained as a yellow oil, was dried under vacuum for several hours. Its structure was confirmed by means of ${ }^{1} \mathrm{H} \mathrm{NMR}\left(\mathrm{CDCl}_{3}, 400 \mathrm{MHz}\right)$ (Figure $\left.\mathrm{S} 1\right)$ : ${ }^{1} \mathrm{H} \mathrm{NMR}\left(\mathrm{CDCl}_{3}, 400 \mathrm{MHz}\right)^{27}\left(3.66\left(\mathrm{~m}, 2 \mathrm{H}, \mathrm{NH}-\mathrm{CH}_{2}\right), 3.55(\mathrm{~s}\right.$, $\left.{ }_{10} 9 \mathrm{H},\left(\mathrm{CH}_{3} \mathrm{O}\right)_{3} \mathrm{Si}\right), 3.46\left(\mathrm{~m}, 2 \mathrm{H}, \mathrm{N}-\mathrm{CH}_{2}\right), 3.20\left(\mathrm{~m}, 2 \mathrm{H}, \mathrm{N}-\mathrm{C} \boldsymbol{H}_{2}\right)$, $2.34\left(\mathrm{~m}, 4 \mathrm{H}, \mathrm{C}(=\mathrm{O})-\mathrm{C} \boldsymbol{H}_{2}\right), 2.17\left(\mathrm{~m}, 2 \mathrm{H}, \mathrm{C}(=\mathrm{O})-\mathrm{CH}_{2}\right), 1.60(\mathrm{~m}$, $6 \mathrm{H}, \mathrm{Si}-\mathrm{CH}_{2} \mathrm{CH}_{2}$ and $\left.\mathrm{C}(=\mathrm{O})-\mathrm{CH}_{2} \mathrm{CH}_{2}\right), 1.29-1.26\left(\mathrm{~m}, 40 \mathrm{H}, \mathrm{CH}_{2}\right)$, $0.88\left(\mathrm{t}, 6 \mathrm{H}, \mathrm{CH}_{2} \mathrm{CH}_{3}\right)$ and $0.58\left(\mathrm{t}, 2 \mathrm{H}, \mathrm{Si}-\mathrm{CH}_{2}\right) \mathrm{ppm}$; and ${ }^{13} \mathrm{C}$ NMR $\left(\mathrm{CDCl}_{3}, 600 \mathrm{MHz}\right)^{27}: 175.13(\mathrm{NHC}=\mathrm{O}), 174.00(\mathrm{NC}=\mathrm{O})$, $1551.43,50.63$ and $50.56\left(\mathrm{NCH}_{2}\right.$ and $\left.\mathrm{OCH}_{3}\right), 36.73,34.23$ and $34.13\left(\boldsymbol{C H}_{2}-\mathrm{C}(=\mathrm{O}) \mathrm{N}, \boldsymbol{C H} \mathrm{H}_{2}-\mathrm{C}(=\mathrm{O}) \mathrm{NH}\right.$ and $\left.\boldsymbol{C} \mathrm{H}_{2}-\mathrm{NH}-\mathrm{C}(=\mathrm{O})\right), 32.00$ $\left(\mathrm{CH}_{2} \mathrm{CH}_{2} \mathrm{CH}_{3}\right), 29.71,29.62,29.59,29.56,29.44,29.41,29.27$, $29.2\left(\mathrm{CH}_{2} \mathrm{CH}_{2} \mathrm{CH}_{2}\right), 25.07\left(\mathrm{CH}_{2}\right), 22.73$ and $22.26\left(\mathrm{Si}-\mathrm{CH}_{2} \boldsymbol{C H}_{2}\right.$ and $\left.\mathrm{CH}_{2} \mathrm{CH}_{2} \mathrm{CH}_{3}\right), 14.14\left(\mathrm{CH}_{2} \boldsymbol{C H}_{3}\right)$ and $6.6\left(\mathrm{Si}-\mathrm{CH}_{2}\right) \mathrm{ppm}$ and ${ }_{20}$ FT-IR: $3499 \mathrm{~cm}^{-1}(\mathrm{vNH}), 2980 \mathrm{~cm}^{-1}\left(\mathrm{v}_{\mathrm{as}} \mathrm{CH}_{3}\right), 2932 \mathrm{~cm}^{-1}\left(\mathrm{v}_{\mathrm{as}} \mathrm{CH}_{2}\right)$, $2866 \mathrm{~cm}^{-1}\left(\mathrm{v}_{\mathrm{s}} \mathrm{CH}_{2}\right), 1739 \mathrm{~cm}^{-1}(\mathrm{vC}=\mathrm{O}), 1650(\mathrm{vC}=\mathrm{O})$ and 1543 $\mathrm{cm}^{-1}(\mathrm{vNH})$.

2.2 Synthesis of $\mathbf{H}$. Precursor $\mathrm{P}$ was first dissolved in 25 dimethyl sulfoxide (DMSO, Riedel-deHaën, dried max. 0.03\% $\mathrm{H}_{2} \mathrm{O}$ ). Bidistilled water and hydrochloric acid $(\mathrm{HCl}, 37 \%$, Pronalab) $1 \mathrm{M}$ were then added (molar ratios of $\left.\mathrm{P}: \mathrm{H}_{2} \mathrm{O}: \mathrm{HCl}: \mathrm{DMSO}=1: 600: 0.4: 138\right)$. The oily mixture was kept in static conditions during one week in an oil bath $\left(80^{\circ} \mathrm{C}\right)$. 30 Ethanol was added to the resulting slurry solution and the latter was left standing during two days at room temperature to precipitate the solid. The solid was then filtered and washed with water until neutral $\mathrm{pH}$ was attained and again washed with ethanol and acetone. The white solid was dried at $50{ }^{\circ} \mathrm{C}$ during 1 35 day.

\subsection{Experimental methods:}

The liquid ${ }^{1} \mathrm{H}$ and ${ }^{13} \mathrm{C}$ Nuclear Magnetic Resonance (NMR) spectra were recorded in deuterated chloroform $\left(\mathrm{CDCl}_{3}\right)$ on a ${ }_{40}$ Bruker Avance III spectrometer (400 MHz) equipped with a TXI probe-head with inverse detection. Chemical shifts $(\delta)$ are reported in parts per million (ppm) relative to tetramethylsilane (TMS) and splitting multiplicities are described as $s=\operatorname{singlet;} t=$ triplet or $m=$ multiplet. Coupling constants ( $J$ values) are 45 reported in Hertz $(\mathrm{Hz})$.

${ }^{29} \mathrm{Si}$ MAS and ${ }^{13} \mathrm{C} \mathrm{CP} / \mathrm{MAS}$ NMR spectra were recorded on a Bruker Avance 400 (9.4 T) spectrometer at 79.49 and 100.62 $\mathrm{MHz}$, respectively. ${ }^{29} \mathrm{Si}$ MAS NMR spectra were recorded with $2 \mu \sigma(\theta \approx 30)$ rf pulses, and recycle delay of $60 \mathrm{~s}$ and at a $5.0 \mathrm{kHz}$ 50 spinning rate. ${ }^{13} \mathrm{C} \mathrm{CP} / \mathrm{MAS}$ NMR spectra were recorded with 4 $\mu$ s $1 \mathrm{H} 90^{\circ}$ pulse, $2 \mathrm{~ms}$ contact time, a recycle delay of $4 \mathrm{~s}$ and at a spinning rate of $8 \mathrm{kHz}$. The $\delta$ are quoted in ppm from TMS.

The XRD patterns were recorded with a Philips X'Pert MPD powder X-ray diffractometer, using monochromated $\mathrm{CuK}_{\alpha}$ 55 radiation $(\lambda=0.154 \mathrm{~nm})$ over a $\mathrm{q}$ range between 0.77 and $25 \mathrm{~nm}^{-1}$.

POM images were recorded using an OPTIKA B-600POL microscope equipped with a $8 \mathrm{Mpixel}$ digital Photo Camera. The images were analyzed using the OPTIKA Vision Pro software.
AFM images were recorded in a Veeco Metrology 60 Multimode/Nanoscope IVA equipment (CEMUP-Porto contract $\mathrm{REEQ} / 1062 / \mathrm{CTM} / 2005)$, in tapping mode using a super sharp silicon tip, curvature radius $10 \mathrm{~nm}$, and frequency resonance equals to $\approx 300 \mathrm{KHz}$. Flattening and elimination of line noise tools and a Lowpass filter provided by the WSXM software ${ }^{33}$ 65 were used to improve the quality of the images.

The microstructure, surface morphology and chemical composition distribution were obtained using a field-emission scanning electron microscope (FEG-SEM Hitachi SU-70 equipped with a Bruker EDS and transmitted electron detector) 70 and TEM (Hitachi H-9000 operating at $300 \mathrm{kV}$ ). The sample was previously deposited onto a carbon-coated $\mathrm{Cu}$ grid. Elemental analyses on microscopic sections of the sample were performed by Energy Dispersive Spectroscopy (EDS). The analysis of the morphology of hybrid A after the thermal treatment was 75 determined at $20 \mathrm{kV}$ on a Hitachi Field Emission S-2700 microscope at low vacuum. The sample was first coated with gold $(\mathrm{Au})$.

The surface wettability of the samples was assessed by means of static contact angle $(\theta)$ measurements using the sessile drop 80 method. The $\theta$ values were measured at room temperature with ultra-pure distilled water using a Contact Angle OCA +15 device (DataPhysics) and SCA-20 software. The samples were analysed as pellets. The volume of the liquid droplets was kept constant at $2 \mu \mathrm{L}$. The results reported correspond to the average value of 85 eight measurements.

ATR/FT-IR spectra were collected on a Thermoscientific Nicolet iS10: smart iTR, equipped with a diamond ATR crystal. For ATR data acquisition, approximately $2 \mathrm{mg}$ of the sample were placed onto the crystal and the spectrum was recorded. An 90 air spectrum was used as reference in absorbance calculations. The sample spectra were collected at room temperature in the $4000-400 \mathrm{~cm}^{-1}$ range by averaging 64 scans at a spectral resolution of $1 \mathrm{~cm}^{-1}$.

The FT-Raman spectra were recorded at room temperature 95 with a Bruker Spectrometer, Model RFS100/S and the laser radiation emitted by the $\mathrm{Nd}$ :YAG with wavelength at $1064 \mathrm{~nm}$. The spectra were collected over $4000-50 \mathrm{~cm}^{-1}$ at a resolution of 4 $\mathrm{cm}^{-1}, 400$ scans (about 20 minutes) and $300 \mathrm{~mW}$ (laser power). To evaluate complex band FT-IR and FT-Raman envelopes and 100 to identify underlying spectral components, the iterative leastsquares curve-fitting procedure in the PeakFit software (version $4)^{34}$ was used extensively throughout this study. The best fit of the experimental data was obtained by varying the frequency, bandwidth and intensity of the bands. Because of the morphology 105 of material under investigation, we employed Voight functions.

DSC measurements were performed using a DSC 204 Netzsch Differential Scanning Calorimeter. A mass of 2-5 mg was placed in $40 \mu \mathrm{l}$ aluminum can and stored in a desiccator over phosphorous pentoxide for one week at room temperature under 110 vacuum. After the drying treatment the can was hermetically sealed and the thermogram was recorded. The sample was heated from 20 to $100{ }^{\circ} \mathrm{C}$ at $10{ }^{\circ} \mathrm{C} \mathrm{min}{ }^{-1}$. The purge gas used in all experiments was high purity nitrogen supplied at a constant 25 $\mathrm{cm}^{3} \min ^{-1}$ flow rate.

115 ATR/FT-IR spectra recorded as function of temperature were obtained with a SPECAC temperature controller in an ATR 
configuration using a High Temperature Golden GateTM MkII ATR Accessory. The spectra were collected in $4000-500 \mathrm{~cm}^{-1}$ range by averaging 64-200 scans and a resolution of $1 \mathrm{~cm}^{-1}$.

The photoluminescence spectra were recorded at room 5 temperature with a modular double grating excitation spectrofluorimeter with a TRIAX 320 emission monochromator (Fluorolog-3, Horiba Scientific) coupled to a R928 Hamamatsu photomultiplier, using a front face acquisition mode. The excitation source was a $450 \mathrm{~W}$ Xe arc lamp. The emission spectra 10 were corrected for detection and optical spectral response of the spectrofluorimeter and the excitation spectra were corrected for the spectral distribution of the lamp intensity using a photodiode reference detector. The emission decay curves at acquired at $12 \mathrm{~K}$ were measured with the setup described for the luminescence 15 spectra using a pulsed Xe-Hg lamp ( $6 \mu$ s pulse at half width and 20-30 $\mu$ s tail). The room-temperature emission decay curves were measured with a TCSPC spectrofluorometer (Horiba Scientific) coupled to a TBX-04 photomultiplier tube module $(950 \mathrm{~V}), 200 \mathrm{~ns}$ timeto-amplitude converter and $70 \mathrm{~ns}$ delay. The 20 exciting source was a Horiba-Jobin-Yvon pulsed diode, (NanoLED-390, peak at $381 \mathrm{~nm}, 1.2 \mathrm{~ns}$ pulse duration, $1 \mathrm{MHz}$ repetition rate, and $150 \mathrm{~ns}$ synchronization delay). The emission quantum yields were measured using the C9920-02 measurement system (Hamamatsu) with a $150 \mathrm{~W}$ Xe lamp coupled to a 25 monochromator for wavelength discrimination, an integration sphere as sample chamber and a multichannel analyzer for signal detection. Three measurements were made for each sample and the average values obtained are reported with accuracy within $10 \%$ according to the manufacturer.

30

\section{Results and discussion}

Seeking the creation of a metastable system, we anticipated to produce a highly temperature-sensitive material. After being synthesized its structure and morphology were characterized in 35 depth in the subsequent weeks and care was taken to register the exact time and temperature at which each of the measurements were performed.
The ${ }^{13} \mathrm{C} \mathrm{CP} / \mathrm{MAS}$ NMR data (Figure S2a and Table S1) confirm the integrity of the organic functional groups of $\mathbf{P}$ (alkyl 40 chains and amide cross-links) in A. A prominent peak around 33 ppm reveals that the great majority of the pendant alkyl chains adopt highly ordered all-trans zigzag conformations. ${ }^{23,35}$ A significantly weaker signal at $30 \mathrm{ppm}$ indicates that the all-trans conformers coexist with a population of gauche conformers. The 45 superposition of the characteristic resonances of the $\mathrm{OCH}_{3}$ and $\mathrm{NCH}_{2}$ moieties prevent any conclusions regarding the completion of the hydrolysis reaction. The ${ }^{29} \mathrm{Si}$ MAS NMR spectrum of $\mathbf{A}$ (Figure S2b and Table S1) exhibits signals at $-50.1 \mathrm{ppm}(5.6 \%$ ), $-58.5 \mathrm{ppm}(48.2 \%)$ and $-68.1 \mathrm{ppm}(46.1 \%)$, assigned to $\mathrm{T}^{1}$ $50\left(\mathrm{CH}_{2}-\mathrm{Si}(\mathrm{OSi})(\mathrm{OR})_{2}\right), \quad \mathrm{T}^{2} \quad\left(\mathrm{CH}_{2}-\mathrm{Si}(\mathrm{OSi})_{2}(\mathrm{OR})\right.$ and $\mathrm{T}^{3} \quad\left(\mathrm{CH}_{2}-\right.$ $\mathrm{Si}(\mathrm{OSi})_{3}$ ) sites, respectively, where $\mathrm{R}$ is $\mathrm{CH}_{3}$ or $\mathrm{H}$. The polycondensation degree $\mathrm{c}\left(\right.$ where $\mathrm{c}=1 / 3\left(\% \mathrm{~A}\left(\mathrm{~T}^{1}\right)+2 \% \mathrm{~A}\left(\mathrm{~T}^{2}\right)+\right.$ $\left.3 \% \mathrm{~A}\left(\mathrm{~T}^{3}\right)\right) \times 100$, A being the integral area) calculated was $80 \%$. This value, higher than reported for $\mathrm{m}-\mathrm{A}(14)\left(74 \%{ }^{27}\right)$, suggests 55 that the introduction of a ramification in the alkyl chain promoted condensation, thus disfavouring the tendency for the formation of a $2 \mathrm{D}$ siloxane network. The empirical formula deduced for $\mathbf{A}$ was $\mathrm{R}^{\prime} \mathrm{Si}(\mathrm{OR})_{0.5}(\mathrm{O})_{1.2}$.

At $q>10 \mathrm{~nm}^{-1}$ (where $q=4 \pi \sin \theta / \lambda, 2 \theta$ being the scattering 60 angle) the XRD pattern of $\mathbf{A}$ exhibits an intense, broad peak centred near $15 \mathrm{~nm}^{-1}$ (Figure 1a) which was decomposed into three components assuming Gaussian band shapes: (1) A peak at $14.3 \mathrm{~nm}^{-1}\left(d_{l}=0.44 \mathrm{~nm}\right.$, with $\left.d=2 \pi / q\right)$ corresponding to amideamide spacings; ${ }^{36}(2)$ A peak at $15.0 \mathrm{~nm}^{-1}\left(d_{2}=0.42 \mathrm{~nm}\right)$ due to ${ }_{65}$ ordering within the siliceous domains, ${ }^{37}$ (3) A peak at $16.0 \mathrm{~nm}^{-1}$ $\left(d_{3}=0.39 \mathrm{~nm}\right)$ assigned to chain-chain distances. ${ }^{21}$ At $q<10 \mathrm{~nm}^{-1}$ the dominating peak at $1.33 \mathrm{~nm}^{-1}$ (Figure 1a) corresponds to the $1^{\text {st }}$ order reflection of a lamellar structure with an interlamellar spacing $l_{1}=4.72 \mathrm{~nm}$ (where $l=n 2 \pi / q_{n}$ ) (black vertical lines in 70 Figure $1 b)$. This distance is slightly smaller than that reported for $\mathrm{m}-\mathrm{A}(14)(5.0 \pm 0.2 \mathrm{~nm}){ }^{27}$ The peak detected at $2.04 \mathrm{~nm}^{-1}$ (Figure $1)$ is attributed to the occurrence of a second lamellar
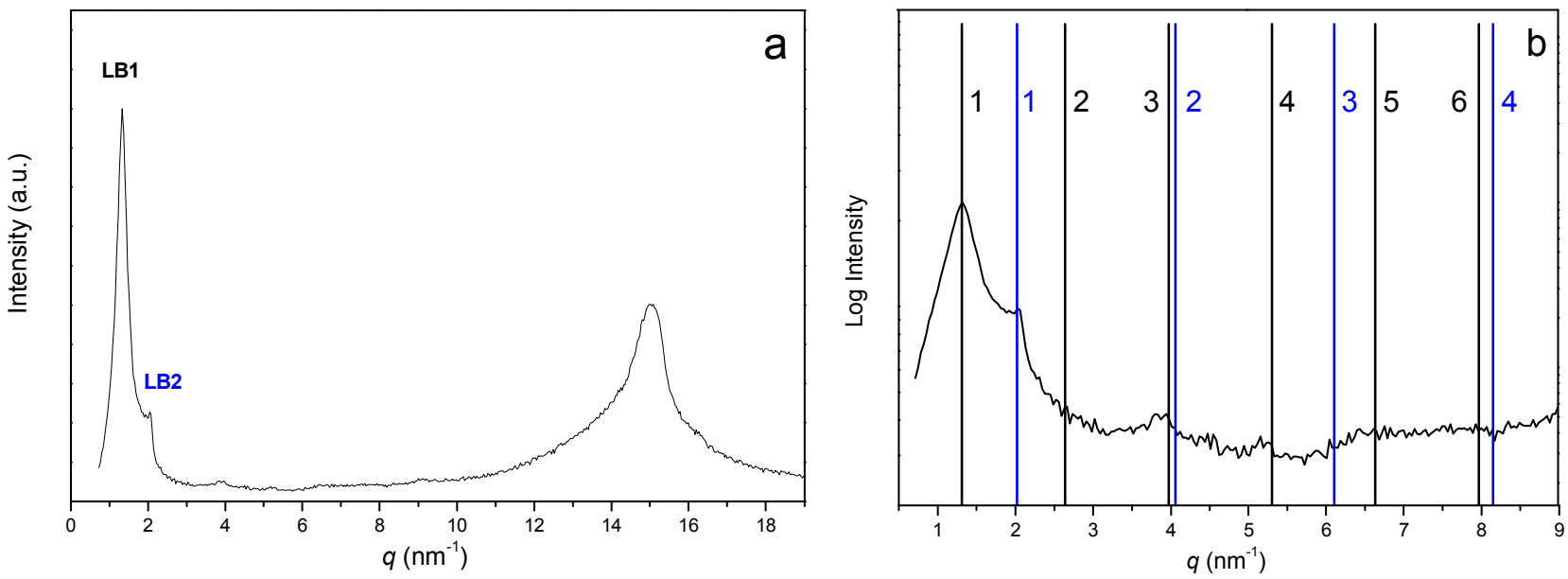

75 Figure 1. Room temperature XRD patterns of hybrid $\mathbf{A}$ in the low-to-high $q$ (a) and low- $q$ (b) ranges recorded before a heating/cooling cycle between room temperature and $70{ }^{\circ} \mathrm{C}$. The vertical black and blue lines in (b) represent the two lamellar bilayer structures initially formed in $\mathbf{A}$ (LB1 and $\mathbf{L B 2}$, respectively). 


\title{
Cite this: DOI: $10.1039 / \mathrm{c0xx00000x}$
}

\author{
www.rsc.org/xxxxxx
}

ARTICLE TYPE

structure with a spacing $l_{2}=3.14 \mathrm{~nm}$ (blue vertical lines in Figure $1 \mathrm{~b})$. The spacings $l_{1}$ and $l_{2}$ are correlated with the length of chains 1 and 2 linked to the pyramidal $\mathrm{N}$ atom, respectively (Scheme 1). The distance $l_{1}$ is related with the separation between the 5 siliceous domains of the lamellar bilayer structure LB1, whereas $l_{2}$ is associated with the separation between the siliceous domains of the lamellar bilayer structure LB2 (Figure 1a). While the selfassembly driving forces in LB1 are associated with hydrophobic interactions between the alkyl chains and by hydrogen bonding 10 interactions between neighbour amide groups (chain 1 has a hydrogen donor group and a hydrogen acceptor group), in LB2 self-assembly relies essentially on hydrophobic interactions (chain 2 has solely a hydrogen acceptor group). As the estimation of the theoretical distances by means of ChemBioOffice 11.01 15 software was not conclusive, the degree of interpenetration of the alkyl chains in LB1 and LB2 remains unknown. In the schematic tentative representation of Figure $2 \mathrm{a}$ a very low degree of interdigitation was assumed. The lack of SAXS data prevented the calculation of the coherent lengths $L_{1}$ and $L_{2}$, respectively.

20 The submicrometer birefringence evidenced by POM under crossed polarizers (Figure $2 b$ ) confirms the anisotropic character of $\mathbf{A}$. The birefringent entities are organized along a squareshaped pattern. The AFM image recorded in tapping mode shows that the surface of $\mathbf{A}$ at the nanometer scale (Figure 2c) resembles 25 closely that observed at the micrometer scale (Figure $2 b$ ).

The HR-SEM images demonstrate that A consists essentially of irregular clusters of closed microspheres (Figure 3a) with a texture that mimics lettuce corals (Figure 3c), together with a few hemispheres exhibiting in the core a self-similar branching that 30 reminds closely that of starbust dendrimers (Figure 3b). To the best of our knowledge similar findings were only reported before in the field of hybrid materials by Busch et al. ${ }^{38}$ in a study dealing with the biomimetic fractal growth of fluorapatite in gelatin matrices. These unprecedented results unequivocally demonstrate 35 that we succeeded, as sought, in producing a non- bridged

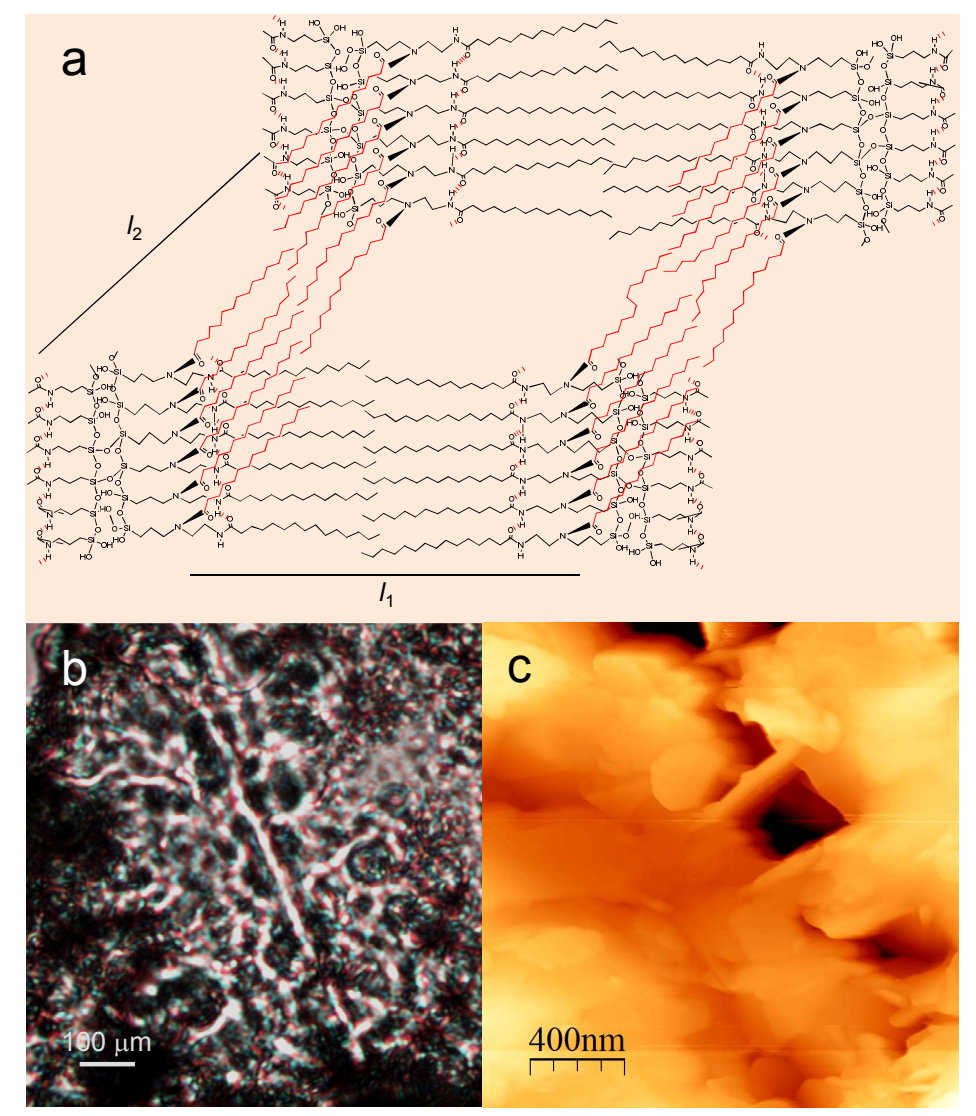

Figure 2. The scheme reproduced in (a) is a tentative representation of one of the possible spatial arrangements of the lamellar structures 40 of hybrid A. The POM (crossed polarizers) (b) and AFM (c) images of hybrid A evidence the occurrence of a square-shaped pattern at the micro- and nanoscales, respectively. 


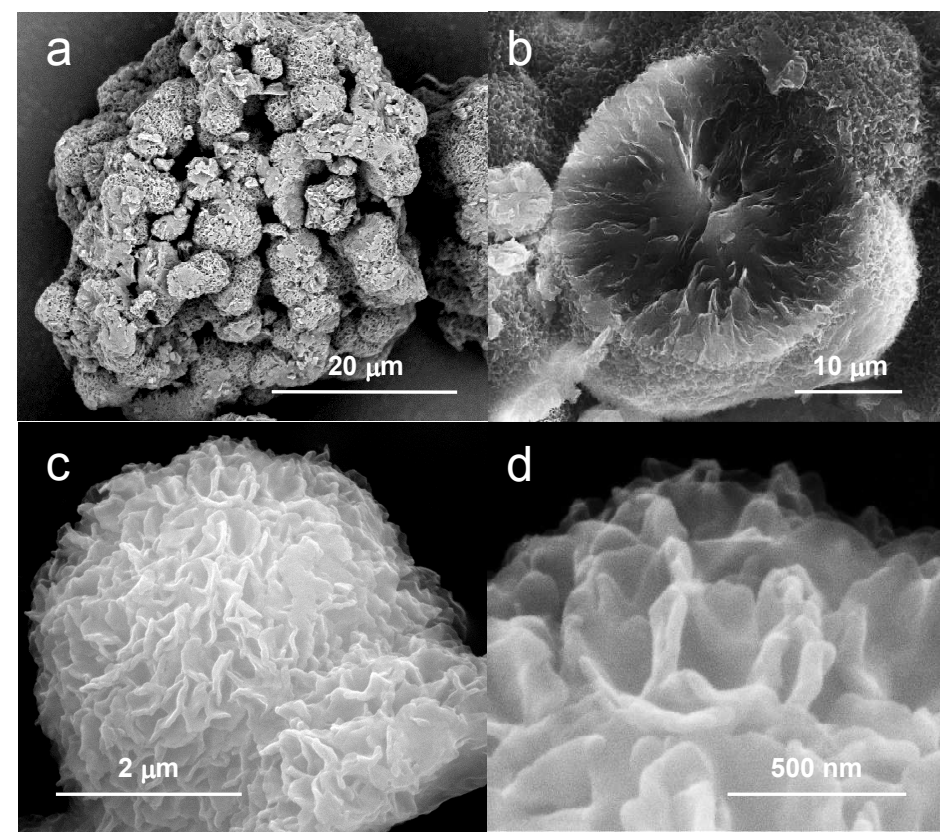

Figure 3. HR-SEM images of hybrid A obtained before the heating/cooling cycle from room temperature up to $70{ }^{\circ} \mathrm{C}$. The synthesized sample formed clusters of closed and broken microspheroids (a). The lettuce coral-like texture of the surface (b-d) and the branching of the core (fractal growth) (b) illustrate the general principles of self-similarity.

5

silsesquioxane material in which the time scale of the morphogenesis is such that we were able to capture two different types of shapes and morphologies that correspond to two distinct stages of the process: the hemispheres, which represent an 10 advanced stage of self-similar branching (fractal growth), and the closed spherocrystals, which correspond to its termination. The nature of the seeds from which growth began and progressed by successive branchings to end up with the closed spheres is unknown. However, considering that the surface of the latter 15 consists of nanoplatelets following the general principles of selfsimilarity (Figures 3c and 3d), we may speculate that the seed may well have been a nanoplatelet. The formation of dumbbellshaped objects, such as those observed in the fluorapatite/gelatin composite system, ${ }^{38}$ would explain the presence of hemispheres 20 in A. The progressive upgrowths of platelets occurring anisotropically at the ends of the seed must have led to the formation of two hemispherical aggregates, then a dumbbell structure and finally a closed sphere. This growth mechanism, extended to the whole sample, would explain the cauliflower-type 25 cluster seen in Figure $3 \mathrm{a}$.

TEM measurements provided evidence that the presence in $\mathbf{A}$ of a tetrahedral $\mathrm{N}$ atom with its characteristic umbrella-like environment (bond angles of ca. $109^{\circ}$ ) promoted a quite unusual organization at the nanoscopic level comprising different ordered
30 nanodomains with variable shape and size. These nanoregions range from typical straight lamellar (arrow in Figure 4a) to z-type lamellar (left upper corner of Figure 4b) arrangements and ultimately to a square-like lamellar pattern (arrow in Figure 4b). The latter ordering geometry is the same as those detected in ${ }_{35}$ Figures $2 \mathrm{~b}$ and $2 \mathrm{c}$ and schematically represented in Figure 2a. The interlamellar distance retrieved from the TEM image (left upper corner of Figure $4 \mathrm{a}$, silica-rich domains are observed as dark regions) and the spacings deduced from XRD are of the same order of magnitude.

40 The static water contact angle $(\theta)$ deduced for hybrid $\mathbf{A}$ was $105 \pm 3^{\circ}$ (Figure S3). The possibility of a preferential distribution of $\mathrm{C}$ atoms (i.e., alkyl chains) at the surface of the micro-objects formed to account for the hydrophobic character was discarded on the basis of the X-ray mapping data (Figure S4). This result 45 strongly suggests that the high $\theta$ value of $\mathbf{A}$ should be associated with the roughness of the surface topography of the sample. ${ }^{39,40}$

The frequency, intensity and fwhm (19 and $14 \mathrm{~cm}^{-1}$, respectively) of the two medium intensity features at $2915 \mathrm{~cm}^{-1}$ (very strong, vS) and $2849 \mathrm{~cm}^{-1}$ (strong, S) in the ATR/FT-IR ${ }_{50}$ spectrum of $\mathbf{A}$ (Figure S5a), assigned to the symmetric and asymmetric $\mathrm{CH}_{2}$ stretching vibration modes $\left(\mathrm{v}_{\mathrm{s}} \mathrm{CH}_{2}\right.$ and $\mathrm{v}_{\mathrm{a}} \mathrm{CH}_{2}$, respectively), ${ }^{41-43}$ indicate that a great proportion of the alkyl 


\section{Cite this: DOI: $10.1039 / \mathrm{c0xx00000x}$}

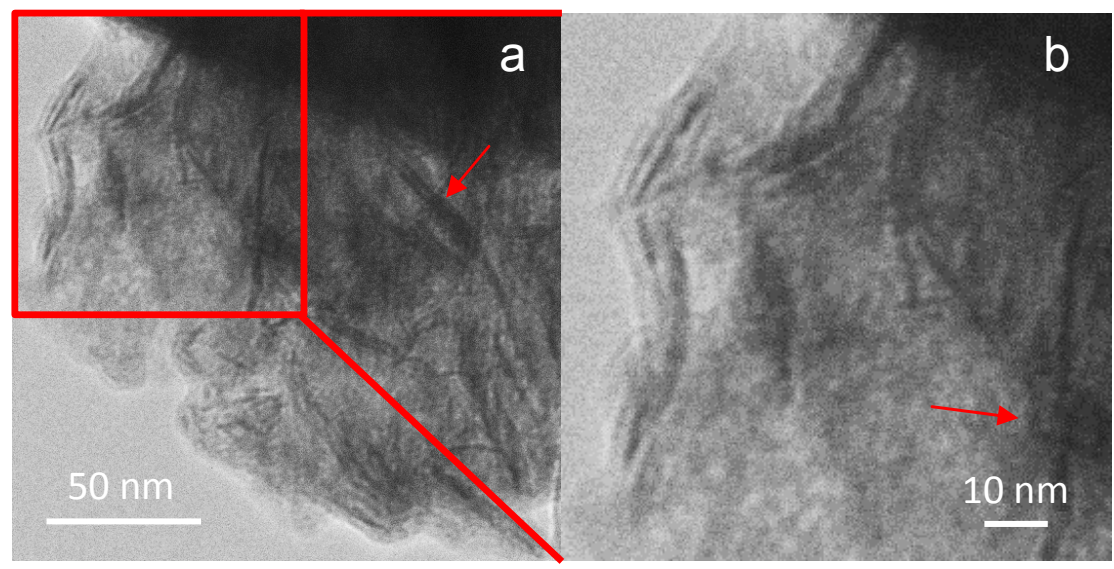

Figure 4. TEM images of hybrid $\mathbf{A}$ reveal the formation of multinanodomains in which lamellar structures adopt different size and shape.

5 chains of $\mathbf{A}$ are fully stretched (all-trans conformations), ordered and tightly packed. ${ }^{41-43}$ In the FT-Raman spectrum the $\mathrm{v}_{\mathrm{a}} \mathrm{CH}_{2}$ and $v_{\mathrm{s}} \mathrm{CH}_{2}$ bands at $2880 \mathrm{~cm}^{-1}(\mathrm{vS})$ and $2847 \mathrm{~cm}^{-1}$ (S) (Figure S5b), respectively, are characteristic of all-trans conformers. ${ }^{43-46}$ The value found for the intensity ratio of these bands $(r=1.32),{ }^{47}$

10 demonstrates that a significant proportion of the alkyl chains of $\mathbf{A}$ adopt, however, gauche conformations. The ATR/FT-IR $\mathrm{CH}_{2}$ bending $\left(\mathrm{\delta CH}_{2}\right)$ band at $1467 \mathrm{~cm}^{-1}$ (Figure S6) confirms the presence of a high fraction of gauche conformers ${ }^{48}$ and the shoulder at $1470 \mathrm{~cm}^{-1}$ reveals that ordering of a fraction of the 15 alkyl chains in the all-trans crystalline state occurs simultaneously. ${ }^{49}$ At last, in the skeletal $\mathrm{C}-\mathrm{C}$ stretching (vC-C) region of the FT-Raman spectrum, in addition to the bands characteristic of all-trans conformations at 1127 and $1062 \mathrm{~cm}^{-1}$, the band at $1084 \mathrm{~cm}^{-1}$ typical of chain randomization (interruption 20 of all-trans conformations), due to the occurrence of gauche conformers, is also seen (Figure S7). ${ }^{44}$ The ATR/FT-IR and FTRaman results are thus in perfect agreement with the ${ }^{13} \mathrm{C}$ CP/MAS NMR data.

The wavenumber difference between the amide I and amide ${ }_{25}$ II intensity maxima in the room temperature ATR/FT-IR spectrum of $\mathbf{A}\left(94 \mathrm{~cm}^{-1}\right)$ indicates that globally the hydrogenbonded array formed in $\mathbf{A}$ is weaker than that of m-A(14) $\left(89 \mathrm{~cm}^{-}\right.$ $\left.{ }^{1}\right){ }^{27}$ The amide I band of $\mathbf{A}$ was resolved into four components at (Figure S8): (i) $1722 \mathrm{~cm}^{-1}$ (very weak, fwhm $=24 \mathrm{~cm}^{-1}$ ), 30 attributed to free $\mathrm{C}=\mathrm{O}$ groups $^{50}$ and absent in $\mathrm{m}-\mathrm{A}(14)^{27}$. This component could be related exclusively with chain 2 (Scheme 1); (ii) $1664 \mathrm{~cm}^{-1}$ (weak, fwhm $=27 \mathrm{~cm}^{-1}$ ), attributed to hydrogenbonded $\mathrm{C}=\mathrm{O}$ groups of disordered amide-amide aggregates ${ }^{48}$ weaker than those found in m-A(14) $\left(1654 \mathrm{~cm}^{-1}\right)^{27}$; (iv) 1641 and $351618 \mathrm{~cm}^{-1}$ (strong, fwhm $=34 \mathrm{~cm}^{-1}$ ), assigned to hydrogenbonded $\mathrm{C}=\mathrm{O}$ groups in ordered amide-amide aggregates. ${ }^{50}$ The amide II components are located at 1558 and $1540 \mathrm{~cm}^{-1}$ (Figure S8), suggesting the presence of hydrogen-bonded aggregates with two distinct degrees of order. We recall that the amide-amide 40 hydrogen-bonded aggregates are formed exclusively in the LB1 structure.

Figure 5a shows the room-temperature emission spectra of $\mathbf{A}$ under different excitation wavelengths. All the spectra are composed of a broad band (fwhm, $\approx 140 \mathrm{~nm}$ ) peaking at $460 \mathrm{~nm}$ 45 for excitation wavelengths between 250 and $330 \mathrm{~nm}$ and deviates towards the red (from 470 to $595 \mathrm{~nm}$ ) as the excitation wavelength increases from 370 to $440 \mathrm{~nm}$, respectively. Such emission features resemble those previously reported for $\mathrm{m}$ $\mathrm{A}(14)^{27}$ (see circles in Figure 5a) and other amorphous analogous 50 hybrids, being attributed to the overlap between two components: one ascribed to the presence of electron-recombination that occur in oxygen related defects within the siliceous backbone and within the amide cross linkages. ${ }^{27,28,37,51-55}$ The excitation spectra were monitored along the emission spectra (Figure 5b), revealing 55 a main component in the UV/blue region $(320-460 \mathrm{~nm})$ and a low-relative intensity one within $240-290 \mathrm{~nm}$.

Similarly to the situation found for the emission features, the excitation spectra resemble those already observed for analogous organic-inorganic hybrids. ${ }^{28,35,51,52}$ Upon increasing the ${ }_{60}$ monitoring wavelength between 420 and $550 \mathrm{~nm}$, the spectral peak position and fwhm of the low intensity UV component remained unaltered, whereas the main UV/blue component enlarged and deviated towards the red. The component at short wavelengths (250-280 nm) and the low- wavelength region of the 65 main band may be preferentially ascribed to the excitation of the siliceous-related states, whereas the high-wavelength component (above $400 \mathrm{~nm}$ ) is attributed to the preferential excitation of the amide-related emission. . $^{2,35,51,52}$ 

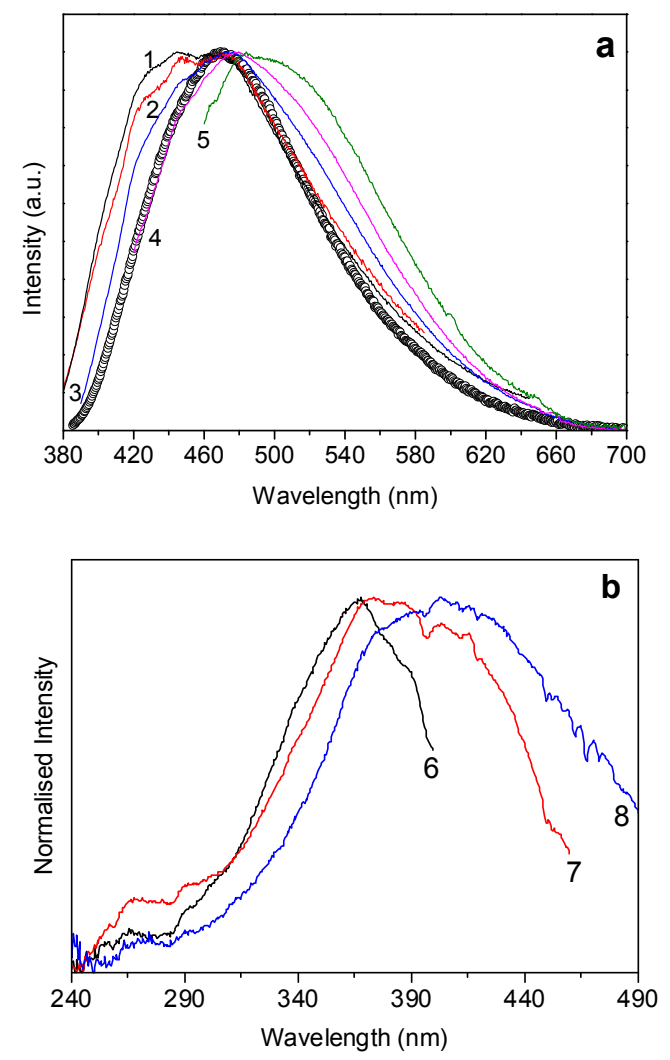

Figure 5. Room-temperature emission (a) and excitation (b) spectra of hybrid A excited at (1) $300 \mathrm{~nm}$, (2) $330 \mathrm{~nm}$, (3) s $370 \mathrm{~nm}$, (4) $400 \mathrm{~nm}$, (5) $440 \mathrm{~nm}$, and monitored at (6) $420 \mathrm{~nm}$, (7) $480 \mathrm{~nm}$, (8) $550 \mathrm{~nm}$, respectively. The emission spectrum of $\mathrm{m}-\mathrm{A}(14)^{11}$ excited at $370 \mathrm{~nm}$ is also shown (circles), demonstrating that the emission and excitation peak position deviates as the excitation and monitoring wavelengths are varied, 10 respectively.

The emission features were quantified through the measurement of the absolute emission quantum yield $(\Phi)$ as a function of the excitation wavelength $(270-440 \mathrm{~nm})$. The higher ${ }_{15} \Phi$ values were measured under preferential excitation with the amide-related emission $(0.08 \pm 0.01$ excited within $360-440 \mathrm{~nm})$. Under preferential excitation with the Si-related emission lower $\Phi$ values were measured $(0.02 \pm 0.01$ excited at $300 \mathrm{~nm}$ and $0.04 \pm 0.01$ excited at $330 \mathrm{~nm}$ ). The fact that the cross-links-related 20 emission has a higher contribution for the overall emission was already demonstrated for amorphous urea- and urethane-derived organic/inorganic hybrids. ${ }^{53,54}$. Comparison of the values obtained with those reported in the literature for several lamellar organic/inorganic hybrids allows concluding that the $\Phi$ values of ${ }_{25} \mathbf{A}$ are smaller than those measured for the AC-m-A(8) monoamidosil $(0.15 \pm 0.02$ excited within $360-360 \mathrm{~nm}),{ }^{54}$ for bridged silsesquioxanes $(0.14 \pm 0.01$ excited within $360-360 \mathrm{~nm}),{ }^{56}$ and for the m-Ut(CY)-AC (Y = 14 and 16) mono-alkyl-urethanesils $(0.11 \pm 0.01$, excited within $350-380 \mathrm{~nm}),{ }^{28}$ being, however 30 identical to that measured for the m-Ut(C22)-AC mono-alkylurethanesil $(0.08 \pm 0.01){ }^{28}$ Moreover, we should also notice that the $\Phi$ value of $\mathbf{A}$ is significantly higher than that of $\mathrm{m}-\mathrm{A}(14)$
$(0.03 \pm 0.01){ }^{27}$ We may thus establish that in lamellar organic/inorganic hybrids both the magnitude of the hydrogen-

35 bonded array formed and the relative polymer weight may impact on $\Phi$.

Further quantitative assessment was performed measuring the time-resolved emission spectra and the emission decay curves at 12 and $300 \mathrm{~K}$ (Figures 6a-6c) excited at 320 and $380 \mathrm{~nm}$ to 40 maximised the relative emission intensity the siliceous and amide-related emission components, respectively. At higher excitation wavelengths $(380 \mathrm{~nm}$, Figure $6 \mathrm{~b})$ the spectra are essentially composed of a broad component at around $525 \mathrm{~nm}$, ascribed to the electron-hole recombinations within the amide 45 cross-linkages. ${ }^{54}$ Upon decreasing the excitation wavelength to $320 \mathrm{~nm}$ (preferential excitation within the siliceous-related component, Figure 6c), the broad component deviated towards the blue $(500 \mathrm{~nm})$ and a series of narrower components, marked with a vertical line in Figures 6b-6c, are superimposed, being 50 ascribed to the presence of the siliceous domains. ${ }^{54}$ The observation of such peaks can be associated with the low condensation ratio ( $80 \%$ ) when compared with the typical values found for analogous amorphous ${ }^{54}$ and lamellar hybrids. The lifetime of the amide-cross linkages- and siliceous-related ${ }_{55}$ emissions were monitored at $480 \mathrm{~nm}$ (excited at $320 \mathrm{~nm}$ ) and at $530 \mathrm{~nm}$ (excited at $380 \mathrm{~nm}$ ) to minimize the spectral overlap. Both emission decay curves are well described by an exponential function yielding lifetime values of $103.0 \pm 8.5 \mathrm{~ms}$ and $75.5 \pm 4.9 \mathrm{~ms}$. We should note that, while the lifetime value of the 60 amide-related emission is of the same order of that found in other similar hybrids, the lifetime value of the siliceous-related component is one order of magnitude higher. ${ }^{54,55}$ An increase in

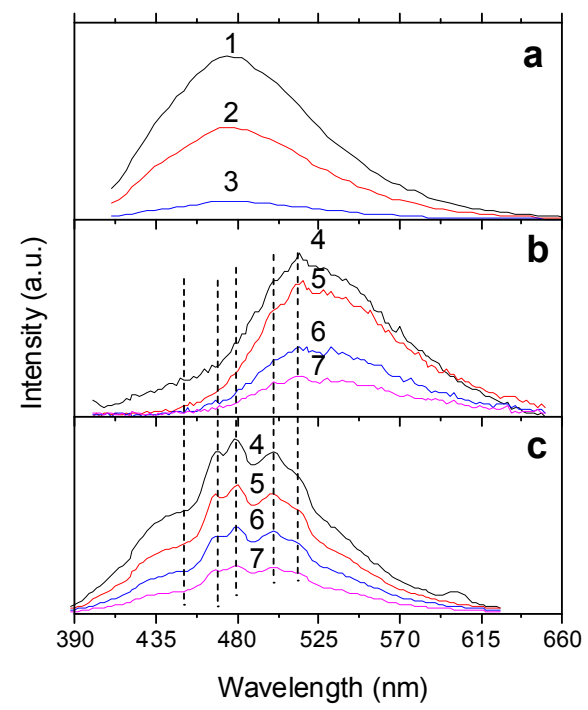

${ }_{65}$ Figure 6. Time-resolved emission spectra of hybrid $\mathbf{A}$ acquired at room temperature excited at $390 \mathrm{~nm}$ (a) and at $12 \mathrm{~K}$ excited at $380 \mathrm{~nm}$ (b) and at $320 \mathrm{~nm}$ (c). The starting delay (SD) values were $0.5 \times 10^{-9} \mathrm{~s}(1), 5.0 \times 10^{-9} \mathrm{~s}(2), 20.0 \times 10^{-9} \mathrm{~s}(3), 0.05 \times 10^{-6} \mathrm{~s}$ (4), $10.00 \times 10^{-6} \mathrm{~s}(5), 50.00 \times 10^{-6} \mathrm{~s}(6)$, and $100.00 \times 10^{-6} \mathrm{~s}(7)$. The 70 emission intensity dependence on the $\mathrm{SD}$ values enables the selective identification of the siliceous and NH-related emission components due to their distinct time scales. 
the lifetime value of the siliceous-related component was also reported for a model compound (containing tetraethoxysilane (TEOS) and propyltrimethoxysilane (PTMOS)) that reproduced the siliceous emission in the absence of the amide-related 5 component. ${ }^{55}$ Therefore, we may suggest that the high lifetime value found for the siliceous related component in $\mathbf{A}$ indicates that the energy transfer processes (siliceous-to-amide) are less efficient than those observed in analogous materials. ${ }^{55}$

At room temperature the emission timescale behind the 10 emission components significantly decreased (curve 1 of Figure 6). The emission spectrum resembles that acquired in steady-state regime (Figure 5a) being formed of a broad component (fwhm $\sim 120 \mathrm{~nm}$ ) peaking at $480 \mathrm{~nm}$, independently of the SD value within $0.5-20.0 \times 10^{-9} \mathrm{~s}$. The emission decay 15 curves were monitored along the band, displaying a nonexponential behaviour. Therefore, an experimental lifetime value for which the emission intensity is reduced to $1 / \mathrm{e}$ of its maximum intensity was considered, yielding a value of $\approx 15 \mathrm{~ns}$.

To determine the temperature of the order/disorder phase 20 transition of the alkyl chains of $\mathbf{A}$ the DSC curve was recorded between room temperature and $90{ }^{\circ} \mathrm{C}$. The DSC data of alkyl chains are known to provide rich information: while the enthalpy change $(\Delta \mathrm{H})$ observed during the fusion of alkyl chains is associated with a large cohesive van der Waals energy term, the 25 entropy change $(\Delta S)$ involves a conformational term, an excluded volume term and a dominating volume expansion term. ${ }^{57}$ The thermogram of $\mathbf{A}$, reproduced in Figure $7 \mathrm{~b}$ (black DSC curve), exhibits a single endothermic peak centred at $54{ }^{\circ} \mathrm{C}\left(\mathrm{T}_{\text {onset }}=42\right.$ $\left.{ }^{\circ} \mathrm{C}, \Delta \mathrm{H}=13.85 \mathrm{~J} \mathrm{~g}^{-1}, \Delta \mathrm{S}=0.265 \mathrm{~J} \mathrm{~g}^{-10} \mathrm{C}^{-1}\right)$, a value significantly 30 lower than that found for $\mathrm{m}-\mathrm{A}(14){ }^{27}$

The analysis of the ATR/FT-IR $v_{\mathrm{a}} \mathrm{CH}_{2}$ and $v_{\mathrm{s}} \mathrm{CH}_{2}$ bands of $\mathbf{A}$ in a heating/cooling cycle (Figures $7 \mathrm{a}$ and $7 \mathrm{~b}$, respectively) followed with the goal of monitoring the changes undergone by the alkyl chains involved in the formation of lamellar structures

${ }_{35}$ LB1 and LB2 during their order/disorder transitions. Upon heating $\mathbf{A}$ from 23 to $85{ }^{\circ} \mathrm{C}$, the $\mathrm{v}_{\mathrm{a}} \mathrm{CH}_{2}$ and $\mathrm{v}_{\mathrm{s}} \mathrm{CH}_{2}$ bands shiftedfrom $2914 \mathrm{~cm}^{-1}$ (fwhm $=19 \mathrm{~cm}^{-1}$ ) and $2848 \mathrm{~cm}^{-1}$ (fwhm $=$ $13 \mathrm{~cm}^{-1}$ ) to 2922 and $2853 \mathrm{~cm}^{-1}$, respectively. These upshifts, whichwere accompanied by band intensity loss and broadening $40\left(\mathrm{fwhm}=25\right.$ and $18 \mathrm{~cm}^{-1}$, respectively, at $\left.85^{\circ} \mathrm{C}\right)$, confirm that the population of alkyl chains in gauche conformations progressively increased, until they became disordered, resembling the liquid $n$ alkanes phase. ${ }^{41}$ Upon subsequent cooling down to room temperature, the frequency and fwhm of the ATR/FT-IR $v_{\mathrm{a}} \mathrm{CH}_{2}$ 45 and $\mathrm{v}_{\mathrm{s}} \mathrm{CH}_{2}$ bands were not restored after approximately 12 months, demonstrating that, unlike in $\mathrm{m}-\mathrm{A}(14)$, in which the bands fully recovered the initial values after $72 \mathrm{~h},{ }^{27}$ the structural changes to which the alkyl chains in A were subject upon heating were not reversible in the period of time indicated.

50 Motivated by this observation, we examined the structural evolution of $\mathbf{A}$ in a heating/cooling cycle between room temperature and $70{ }^{\circ} \mathrm{C}$ by means of XRD. The XRD pattern recorded 2 months after performing this thermal treatment demonstrates dramatic changes (Figure 8): (1) The most ${ }_{55}$ prominent peak at $1.33 \mathrm{~nm}^{-1}$ (black vertical lines in Figures $8 \mathrm{~b}$ ), associated with lamellar structure $\mathbf{L B 1}$, was shifted to $1.24 \mathrm{~nm}^{-1}$

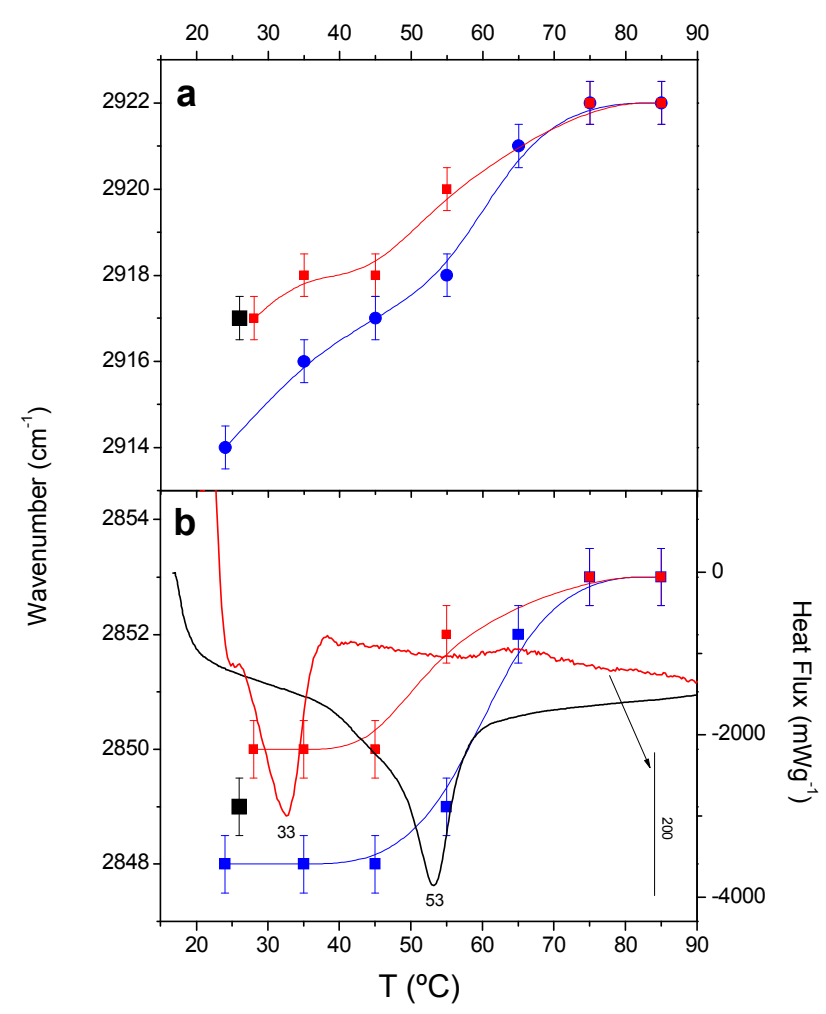

Figure 7. Temperature dependence of the frequency of the ATR/FT-IR $v_{\mathrm{a}} \mathrm{CH}_{2}$ (a) and $\mathrm{v}_{\mathrm{s}} \mathrm{CH}_{2}$ (b) bands (left axis) of hybrid A ${ }_{60}$ during heating (blue squares) and cooling (red squares). The red and blue lines drawn are just guides for the eyes. The black squares, which represent the values of the intensity maxima of the $v_{\mathrm{a}} \mathrm{CH}_{2}$ and $v_{\mathrm{s}} \mathrm{CH}_{2}$ bands measured regularly during 12 months after the heating/cooling cycle, reveal that after this period of ${ }_{65}$ time the alkyl chains of A remained in a metastable state. The DSC curves (right axis) in (b) represent the thermograms recorded before (black line) and 6 months after (red line) heating. The changes in the endotherm produced by heating show that the energetics of A changed dramatically.

70

(red vertical lines in Figure 8b), indicating the formation of a new lamellar structureLB3 with an interlamellar distance slightly larger $\left(l_{3}=5.06 \mathrm{~nm}\right)$ than that of $\mathbf{L B 1}\left(l_{1}=4.72 \mathrm{~nm}\right)$. (2) The peaks related with lamellar structure $\mathbf{L B 2}$ are no longer observed, 75 a proof that heating $\mathbf{A}$ up to $70{ }^{\circ} \mathrm{C}$ led to the destruction of this crystalline phase. (3) The intensity of the band centred at $15 \mathrm{~nm}^{-1}$ suffered a marked reduction.

The HR-SEM images of hybrid A obtained 6 months after this heating/cooling cycle beautifully corroborate the XRD data. 80 Indeed Figure $9 \mathrm{~b}$ shows that after this period of time A exhibits a typical lamellar structure instead of clusters of microspheres and micro-hemispheres (Figure 3a). In the thermogram of $\mathbf{A}$ recorded also 6 months after heating (red DSC curve in Figure $7 \mathrm{~b}$ ) the endotherm is centered at much lower temperature $\left(33^{\circ} \mathrm{C}, \mathrm{T}_{\text {onset }}=\right.$ ${ }_{85} 26^{\circ} \mathrm{C}$ ). In addition the corresponding values of $\Delta \mathrm{H}$ and $\Delta \mathrm{S}$ suffered a marked reduction $\left(1.29 \mathrm{~J} \mathrm{~g}^{-1}\right.$ and $0.049 \mathrm{~J} \mathrm{~g}^{-10} \mathrm{C}^{-1}$, respectively), a clear evidence that, as expected, the energetics of the material were significantly modified by the thermal treatment. 

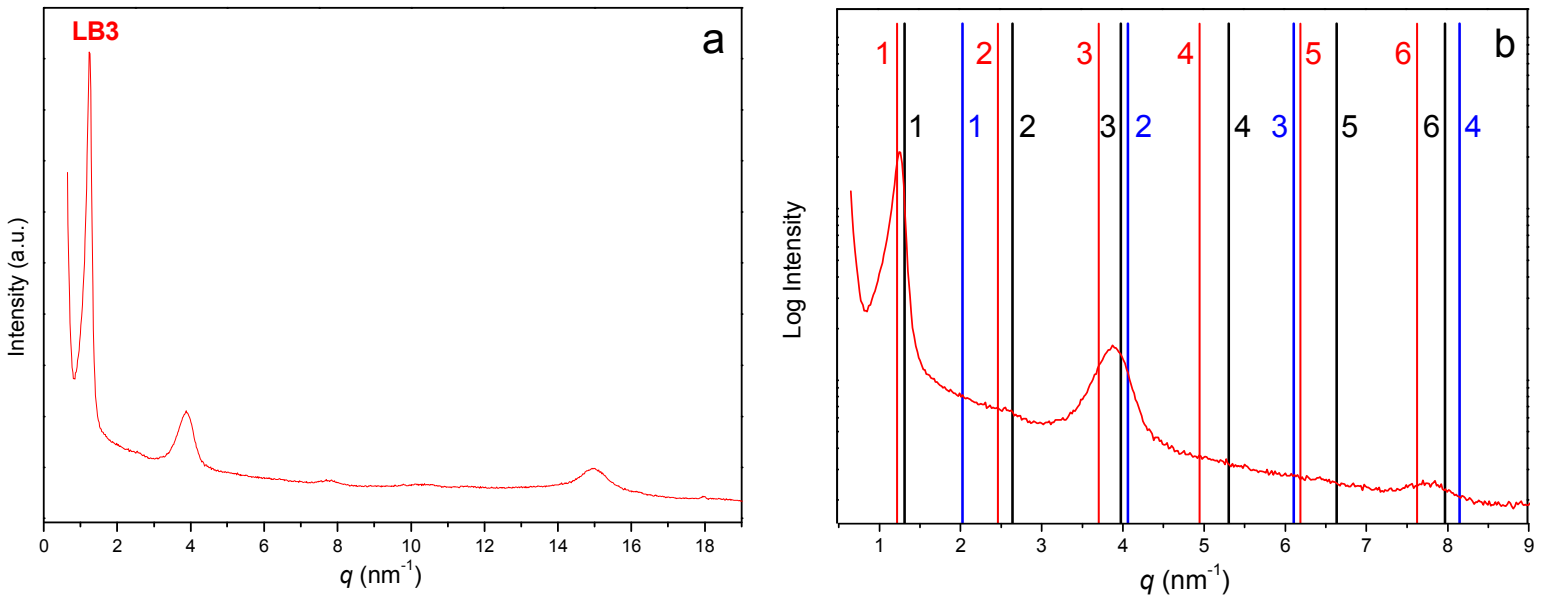

Figure 8. Room temperature XRD patterns of hybrid $\mathbf{A}$ in the low-to-high $q$ range recorded 2 months after a heating/cooling cycle between room temperature and $70{ }^{\circ} \mathrm{C}$ (a). The low- $q$ range shown in (b) reveals that after the thermal treatment one of the two lamellar bilayer structures initially formed in $\mathbf{A}$ is no longer present (LB2, vertical blue lines), whereas LB1 (vertical black lines) is slightly 5 modified and transformed into structure LB3 (vertical red lines).

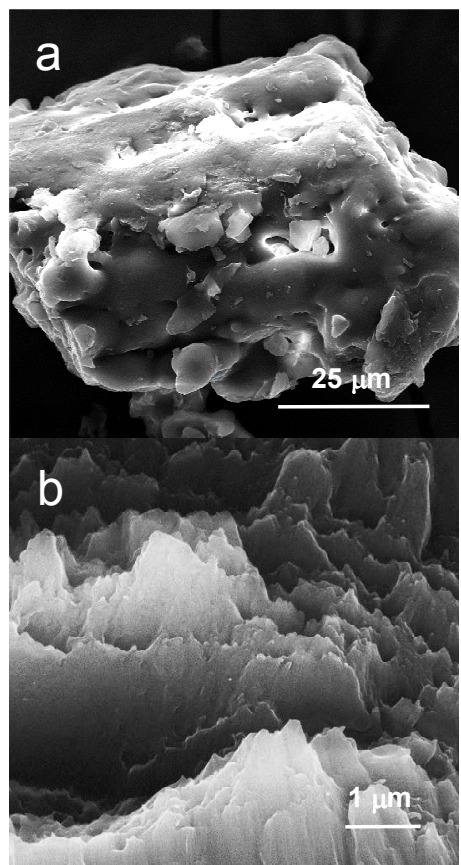

Figure 9. HR-SEM images of hybrid A obtained after the 10 heating/cooling cycle from room temperature up to $70^{\circ} \mathrm{C}$. After being subject to a heating/cooling cycle the morphology of $\mathbf{A}$ changed into a typically lamellar one (not shown). This texture remained unchanged after leaving the sample at room temperature for 6 months (b).
The emission spectra excited at $365 \mathrm{~nm}$ were also studied as function of heating/cooling cycles with a maximum temperature value of $54{ }^{\circ} \mathrm{C}$. The overall emission spectrum acquired at $20{ }^{\circ} \mathrm{C}$ (black line in Figure 10) underwent a red-shift after heating up to ${ }_{20} 54{ }^{\circ} \mathrm{C}$ (red line in Figure 10) due to a decrease in the relative intensity of the low-wavelength region. After cooling, the emission spectrum remained essentially identical to that acquired at $54{ }^{\circ} \mathrm{C}$. The non-reversibility of the emission features after the heating/cooling cycle is illustrated in Figure 10, where the

25 emission spectrum acquired $\sim 350 \mathrm{~h}$ after the end of the thermal cycle is reproduced (blue line). The emission dependence of the photoluminescence on heating/cooling cycles was previously studied for m-A(14). ${ }^{27}$ Similarly to the situation found for the latter hybrid, ${ }^{27}$ in $\mathbf{A}$ the siliceous-related component is 30 approximately independent of the variation of temperature, whereas the NH-related emission deviates towards the red (Figure 10). In $\mathrm{m}-\mathrm{A}(14)$ the reversal of the NH-related emission energy at the end of the thermal cycle back to the initial value was complete after ca. $300 \mathrm{~h}$, demonstrating that the rate of 35 conformational recovery of the alkyl chains was much faster than the rate of rebuilding of the amide-amide hydrogen-bonded network. ${ }^{27}$ Here the emission features after the end of the thermal cycle did not recover the properties measured prior to the thermal cycle (energy and fwhm). These findings provide additional 40 support to the explanation that the ramification of the pendant alkyl chain of m-A(14) impacted negatively on the reversibility of the order/disorder phase transition of $\mathbf{A}$. 


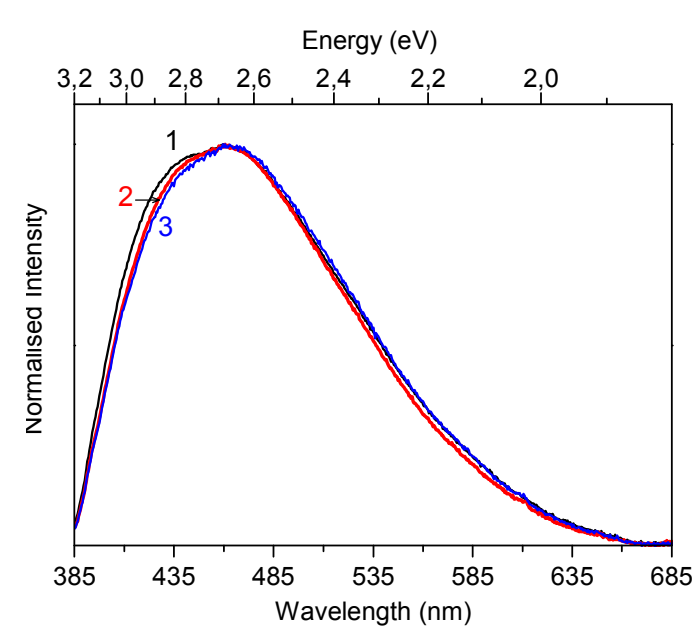

Figure 10. Emission spectra of hybrid A excited at $365 \mathrm{~nm}$ as function of heating-cooling cycle and acquired prior to heating at $20{ }^{\circ} \mathrm{C}(1)$, at the end of the thermal cycle at $54{ }^{\circ} \mathrm{C} \mathrm{(2)} \mathrm{and} 350 \mathrm{~h}$ 5 after the end of the heating cycle at $20^{\circ} \mathrm{C}$ (3), demonstrating the non-reversibility of the emission features after the heating/cooling cycle.

Let us now recall the dynamics of complexity of m-A(14), a 10 stable material obtained via self-directed assembly. ${ }^{27}$ The energetics of its order/disorder transition involves a synergy between van der Waals interactions and hydrogen bonding, the order/disorder transition of the pendant alkyl chains controlling, but being simultaneously governed by the destruction/formation 15 of the amide-amide hydrogen-bonded array. In this material each pendant alkyl chain grafted to the siliceous network contains an amide group which easily interacts with two neighbour amide groups, thus forming highly directional hydrogen bonds. Understandably, the annihilation of the hydrogen bonds at 20 increasing temperature leads to major structural changes, inducing in particular the randomization of the alkyl chains. After cooling $\mathrm{m}-\mathrm{A}(14)$ remains in a metastable state until it recovers the initial state. Two processes with rather different rates operate at this stage: the conformational recovery of the polymer chains 25 (terminated after $72 \mathrm{~h}$ ) and the rate of reformation of the hydrogen-bonded array (complete after $300 \mathrm{~h}$ ). The latter process clearly relies on the efficient self-association occurring between neighbour amide groups.

The inclusion of a ramification in the pendant alkyl chain of $30 \mathrm{~m}-\mathrm{A}(14)$ changed dramatically the entire scenario. In $\mathbf{A}$ the arrangement of the two pendant alkyl chains is dictated by a tetrahedral $\mathrm{N}$ atom which imposes angles of ca. $109^{\circ}$ and therefore introduces severe steric restrictions for the formation of a highly directional amide-amide hydrogen-bonded array 35 involving exclusively chains 1 . Hence the rate of crystallization of A was deeply reduced, explaining the substantial changes observed in the global properties as a function of time. For instance, close monitoring of the endothermic peak associated with the order/disorder phase transition of the alkyl chains by ${ }_{40}$ DSC measurements demonstrated the time-dependence of the alltrans/gauche conformational ratio. As expected, a shift of the endotherm towards higher temperatures occurred with time (not shown), corresponding to an increase in the proportion of alltrans conformers as crystallization progressed. As a result of this 45 combined effect (i.e., restricted hydrogen bond formation and constrained conformational evolution of the alkyl chains) the complex system dynamics are substantially more complicated than those described for m-A(14). In contrast with m-A(14), asprepared material $\mathbf{A}$ is a metastable state in which dominating all50 trans conformers coexist with gauche conformers. At the end of a heating cycle between room temperature and $85^{\circ} \mathrm{C}$, metastable $\mathbf{A}$ contained disordered alkyl chains $\mathbf{1}$ and $\mathbf{2}$, and a high concentration of free (non-bonded) amide groups resulting from a major breakdown of the amide-amide aggregates. During cooling

${ }_{55}$ the reformation of the hydrogen bonds and the recovery of the conformational state of the alkyl chains to rebuild structures LB1 and LB2 was severely limited by the steric constraints. The selfassociation between amide groups of chains 1 was favoured and a new lamellar structure (LB3) with an interlamellar distance 60 similar to that of LB1 emerged. The crystallization of phase LB2 did not occur, however, in the period of time analysed, a result that is consistent with the fact that after 12 months a great proportion of alkyl chains have still not adopted all-trans conformations. Therefore after heating $\mathbf{A}$ reached another ${ }_{65}$ metastable state, different from the initial one. This effect led to the substantial changes in the global properties of $\mathbf{A}$.

In conclusion, both stable $\mathrm{m}-\mathrm{A}(14)$ and metastable $\mathbf{A}$ share in common the fact that upon being perturbed (i.e., heated) they become highly frustrated and stressed. ${ }^{58}$ However the subsequent 70 dynamics which aim at relaxing and optimizing the system are different. In the case of m-A(14), the system is able to find within a measurable amount of time combined dynamical moves between the components that collectively lead to the improvement of the distribution of configurations. ${ }^{58}$ The system 75 progressively releases the strain, yielding consecutive metastable configurations with increasing stability and taking around $300 \mathrm{~h}$ to reach the most stable configuration. This time-dependent evolution displays a logarithmic nature, ${ }^{27}$ closely reminding the Tangled Nature model of evolutionary ecology. ${ }^{58}$ Hybrid $\mathbf{A}$, in 80 which the number of degrees of freedom is much higher, is clearly less efficient in fulfilling the constraints dictated by the mutual interactions which take place between the various components. Heating simply sends the system into a metastable state different and less stable than that present prior to the thermal 85 treatment After 12 months the stability has not been reached. It is of interest to refer at this stage that Anderson et al. ${ }^{58}$ introduced the notion of quakes to explain the evolution of complex systems. According to these authors, the dynamics of these systems do not act always in a coherent and constructive way and a significant 90 number of intermediate metastable states will have to be reached before the system becomes stable. The inbuilt strain of the initial configuration exerts a directed push on all the components and will once in a while lead to coherent rearrangements of parts of the system. These essential events (quakes) will act as ${ }_{95}$ earthquakes in a geological fault, inducing irreversible changes in the properties of the system. In the case of $\mathbf{A}$, heating may be viewed as an external quake. 
Thus it may be stated that in practice the two materials basically differ in their temporal evolution. The present study, spanning 12 months, has enabled us to push the formation of an ordered non-bridged silsesquioxane system from self-assembly to 5 self-organization conditions simply through a judicious design of the precursor. This has made possible the detection in the new hybrid material of unprecedented evidences of intermediate steps of morphogenesis manifested as fractal growth. The study of the structural changes induced in the system upon heating above the 10 order/disorder phase transition of metastable $\mathbf{A}$ allowed us demonstrating how sensitive this material is to thermal treatments.

\section{Conclusions}

15 We report a new member of the amidosil family of hybrids, termed A, which differs chemically from the parent lamellar bilayer m-A(14) material by the fact that the pendant alkyl chain has been ramified into two alkyl chains with about the same length via a tertiary amide group. The modification introduced in 20 the precursor design gave rise to two lamellar bilayer structures, which induced the formation of a series of unique nanoregions, some of which were manifested at the microscale. Because of its particularly rough texture, mimicking lettuce corals, A is hydrophobic. The hybrid system A has complex dynamics and 25 undergoes a self-organization process instead of the self-directed assembly which led to the formation of $\mathrm{m}-\mathrm{A}(14)$. Because of the slow evolution of this non-bridged silsesquioxane material it became possible to detect unprecedented proofs of intermediate steps of fractal growth. The order/disorder phase transition of the 30 alkyl chains of metastable A occurs at lower temperature than in $\mathrm{m}-\mathrm{A}(14)$. Heating above this temperature pushed A into another state of metastability which could be described through several macroscopic measurements. As we write the system is still evolving, i.e., relaxing its strain towards greater stability at a 35 longer time scale. In addition this work raises an important issue. It strongly suggests that ordered non-bridged silsesquioxane hybrids may be extremely sensitive to temperature (e.g., day-tonight temperature changes) and that consequently characterization analyses of this type of materials should be 40 repeated several times at different periods to avoid misleading conclusions about their apparent stability.

\section{Acknowledgements}

This work was supported by Fundação para a Ciência e a Tecnologia 45 (FCT) and FEDER (contracts PTDC/QUI-QUI/100896/2008, PTDC/CTM-BPC/112774/2009, PEst-C/CTM/LA0011/2011, PestC/CTM/LQ0011/2013, Pest-OE/QUI/UI0616/2014 and PEstOE/SAU/UI0709/2014) and by COST Action No MP1202 "Rational Design of Hybrid Interfaces". S. C. Nunes acknowledges FCT for a 50 grant (SFRH/BPD/63152/2009). The authors thank Dr. Sónia Sousa and Prof. Ana Ramos (University of Beira Interior) for the contact angle measurements.

\section{Notes}

${ }^{a}$ Chemistry Department and CICS - Health Sciences Research Centre, 55 University of Beira Interior, 6200-001Covilhã,Portugal.; snunes@ubi.pt ${ }^{b}$ Chemistry Department, University of Trás-os-Montes e Alto Douro, 5000-801 Vila Real, Portugal; vbermude@utad.pt
${ }^{c}$ Physics Department and CICECO, University of Aveiro, 3810-193 Aveiro,Portugal,rferreira@ua.pt

${ }_{60}{ }^{d}$ Materials and Engineering Department and CICECO, University of Aveiro, 3810-193 Aveiro, Portugal; marta.ferro@ua.pt e $3 B$ 's Research Group - Biomaterials, Biodegradables and Biomimetics, University of Minho, Headquarters of the European Institute of Excellence on Tissue Engineering and Regenerative Medicine, AvePark, 65 4806-909, Taipas, Guimarães, Portugal.; jmano@dep.uminho.pt ${ }^{f} I C V S / 3 B$ 's - PT Government Associate Laboratory, Braga/Guimarães, Portugal.

${ }^{g}$ CQ-VR, University of Trás-os-Montes e Alto Douro, 5000-801 Vila Real, Portugal;vbermude@utad.pt

70

$\digamma$ The manuscript was written through contributions of all authors. / All authors have given approval to the final version of the manuscript. The authors declare no competing financial interest.

$75 \ddagger$ Footnotes should appear here. V. de Zea Bermudez: E-mail address: vbermude@utad.pt; Tel: +351-259-350253; Fax: +351-259-350480 S.C.Nunes: E-mail address: snunes@ubi.pt; Tel: +351-275319730; Fax: $+351-275319730$

80 Electronic Supplementary Information (ESI) available: $\left[{ }^{1} \mathrm{H}\right.$ RMN, ${ }^{13} \mathrm{C}$ $\mathrm{RMN}$, and IR data of $\mathrm{P} ;{ }^{13} \mathrm{C} \mathrm{CP} / \mathrm{MAS} \mathrm{RMN},{ }^{29} \mathrm{Si}$ MAS NMR, static water contact angle, EDS mapping, FT-IR $v_{\mathrm{a}} \mathrm{CH}_{2}, v_{\mathrm{s}} \mathrm{CH}_{2}, \delta \mathrm{CH}_{2}$, amide I and amide II regions; FT-Raman $v_{\mathrm{a}} \mathrm{CH}_{2}, v_{\mathrm{s}} \mathrm{CH}_{2}$ and $v \mathrm{C}-\mathrm{C}$ regions og H]. See DOI: $10.1039 / \mathrm{b} 000000 \mathrm{x} /$

85

\section{References}

1 K. Vallé, P. Belleville, F. Pereira and C. Sanchez, Nature Mater., 2006, 5, 107-111.

90 2. P. W. Anderson, Science, 1972, 177, 393-396.

3. N. Goldenfeld and L. P. Kadanoff, Science, 1999, 284, 87-90.

4. J. Aizenberg, C. Weaver, M. S. Thanawala, V. C. Sundar, D. E. Morse and P. Fratzl, Science, 2005, 309, 275-278.

5. S. Nikolov, M. Petrov, L. Lymperakis, M. Friák, C. Sachs, H.-O. 95 Fabritius, D. Raabe and J. Neugebauer, Adv. Mater., 2010, 22, 519526.

6. B. Mendelbrot, Science, 1967, 156, 636-638.

7. R. B. Laughlin and D. Pines, Proc. Nat. Acad. Sci. USA, 2000, 97, 28-31.

100 8. M. Boncheva and G. M. Whitesides, MRS Bulletin, 2005, 30, 736742.

9. G. M. Whitesides, J. K. Kriebel and B. T. Mayers, in W. T. S. Huck (Ed), In Nanoscale Assembly. Chemical techniques. Ch. 9. Berlin: Springer, 2005.

105 10. G. M. Whitesides and B. Grzybowski, Science, 2002, 295, 2418 2421.

11. S. Mann, S. L. Burkett, S. A. Davis, C. E. Fowler, N. H. Mendelson, S. D. Sims, D. Walsh and N. T. Whilton, Chem. Mater., 1997, 9, 2300-2310.

110 12. E. Dujardin and S. Mann, Adv. Mater., 2002, 14, 775-788.

13. G. A. Ozin and A. C. Arsenault, Nanochemistry. A Chemical Approach to Nanomaterials, RSC Publishing, 2006.

14. J. D. Halley and D. A. Winkler, Complexity, 2008, 14, 10-16.

15. G. Nicolis and I. Prigogine, Self-Organization in Non-equilibrium 115 Systems, Wiley, New York, 1977.

16. P. Gomez-Romero and C. Sanchez, Functional Hybrid Materials, Wiley Interscience, New York, 2003.

17. C. Sanchez, B. Julián, P. Belleville and M. Popall, J. Mater. Chem., 2005, 15, 3559-3592.

120 18. C. J. Brinker and G. W. Scherer, Sol-gel Science: The Physics and Chemistry of Sol-Gel Processing, Academic Press, San Diego, CA, 1990.

19. J. J. E. Moreau, L. Vellutini, M. Wong Chi Man, C. Bied, J.-L. Bantignies, P. Dieudonné and J.-L. Sauvajol, J. Am. Chem. Soc., 2001, 123, 7957-7958.

20. J. J. E. Moreau, L. Vellutini, M. Wong Chi Man and C. Bied, Chem Eur J., 2003, 9, 1594-1599. 
21. J. J. E. Moreau, B. P. Pichon, M. Wong Chi Man, C. Bied, H. Pritzkow, J.-L. Bantignies, P. Dieudonné and J.-L. Sauvajol, Angew. Chem. Int. Ed., 2004, 43, 203-206.

22. A. Shimojima, Y. Sugahara and K. Kuroda, Bull Chem Soc Jpn., 1997, 70, 2847-2853.

23. A. N. Parikh, M. A. Schivley, E. Koo, K. Seshadri, D. Aurentz, K. Mueller and D. L. Allara, J. Am. Chem. Soc., 1997, 119, 3135-3143.

24. A. Shimojima and K. Kuroda, Angew. Chem. Int. Ed., 2003, 42 4057-4060.

1025 A. Shimojima, Z. Liu, T. Ohsuna, O. Terasaki and K. Kuroda, J. Am. Chem. Soc., 2005, 127, 14108-14116.

26. S. Sakamoto, A. Shimojima, K. Miyasaka, J. Ruan, O. Terasaki and K. Kuroda, J. Am. Chem. Soc., 2009, 131, 9634-9635.

27. L. D. Carlos, V. de Zea Bermudez, V. S. Amaral, S. C. Nunes, N. J.

15 O. Silva, R. A. S. Ferreira, C. V. Santilli, D. Ostrovskii and J. Rocha, Adv. Mater., 2007, 19, 341-348.

28. M. Fernandes, X. Cattoen, R. A. S. Ferreira, L. D. Carlos, M. W. Chi Man and V. Bermudez, J. Sol-Gel Sci. \& Tech., 2012, 65, 61-73.

29. S. C. Nunes, J. Planelles-Aragó, R. A. Sá Ferreira, L. D. Carlos and

20 V. de Zea Bermudez, Eur. J. Inorg. Chem., 2010, 18, 2688-2699.

30. S. C. Nunes, R. A. S. Ferreira, L. D. Carlos, P. Almeida and V. de Zea Bermudez, J. Phys. Chem. B, 2013, 117, 14529-14543.

31. S. C. Nunes, C. B. Ferreira, J. Hümmer, R. A. S. Ferreira, L. D Carlos, P. Almeida and V. de Zea Bermudez, J. Mater Chem C., $25 \quad 2013,1,2290-2301$.

32. S. C. Nunes, V. T. Freitas, R. A. S. Ferreira, L. D. Carlos, P. Almeida, V. de Zea Bermudez, J. Sol-Gel Sci. Technol., 2014, 72, 239-251.

33 I. Horcas, R. Fernández, J. Gómez-Rodríguez, J. Colchero and J. 30 Gómez-Herrero, Rev. Sci. Instrum., 2007, 78, 13705-13708.

34. Peakfit is a product of Jandel Corporation, 2591 Rerner Boulevard, San Rafael, CA 94901, U.S.A

35. J. Clauss, K. Schmidt-Rohr, A. Adam, C. Boeffel and H. W. Spiess, Macromolecules, 1992, 25, 5208-5214.

35 36. C. Bohm, F. Leveiller, D. Jacquemain, H. Mohwald, K. Kjaer, J. Als-Nielsen, I. Weissbuch and L. Leiserowitz, Langmuir, 1994, 10, 830-836.

37. L. D. Carlos, V. de Zea Bermudez, R. A. S. Ferreira, L. Marques and M. Assunção, Chem. Mater., 1999, 11(3), 581-588.

40 38. S. Busch, H. Dolhaine, A. DuChesne, S. Heinz, O. Hochrein, F. Laeri, O. Podebrad, U. Vietze, T. Weiland and R. Kniep, Eur. J. Inorg. Chem., 1999, 1643-1653.

39. R. N. Wenzel, J. Phys. Colloid Chem., 1949, 53, 1466-1467.
40. A. B. D. Cassie and S. Baxter, Trans. Faraday Soc., 1944, 40, 546551.

41. M. D. Porter, T. B. Bright, D. L. Allara and C. E. D. Childsey, J. Am. Chem Soc., 1987, 109, 3559-3568.

42. S. Singh, J. Wegmann, K. Albert and K. Muller, J. Phys. Chem. B 2002, 106, 878-888.

50 43. R. G. Snyder, H. L. Strauss and C. A. Ellinger, J. Phys. Chem., 1982, 86, 5145-5150

44. N. V. Venkataram and S. Vasudevan, J. Phys. Chem. B, 2001, 105, 7639-7650.

45. N. V. Venkataram, S. Bhagyalakshmi, S. Vasudevan and R. 55 Seshachi, Phys. Chem. Chem. Phys., 2002, 4, 4533-4538.

46. R. Wang, G. Baran and S. L Wunder, Langmuir, 2000, 16, 62986305 .

47. K. G. Brown, E. Bicknell-Brown and M. Ladjadj, J. Phys. Chem., 1987, 91, 3436-3442..

60 48. R. A. Vaia, R. K. Teukolsky and E. P. Gianneli, Chem. Mater., 1994, 6, 1017-1022.

49. H. Hagemann, H. L. Strauss, and R. G. Snyder, Macromolecules, 1987, 20, 2810-2819.

50. D. J. Skrovanek, P. C. Painter and M. M. Coleman, Macromolecules, 1986, 19, 699-705.

51. L. D. Carlos, R. A. S. Ferreira, R. N. Pereira, M. Assunção and V. de Zea Bermudez, J. Phys. Chem. B, 2004, 108, 14924-14932.

52. S. S. Nobre, X. Cattoën, R. A. S. Ferreira, C. Carcel, V. Zea Bermudez, M. Wong Chi Man and L. D. Carlos, Chem. Mater., 2010, 22, 3599-3609.

53. L. Fu, R. A. S. Ferreira, N. J. O. Silva, L. D. Carlos, V. Zea Bermudez and J. Rocha, Chem. Mater., 2004, 16, 1507-1516.

54. S. C. Nunes, N. J. O. Silva, J. Hummer, R. A. S. Ferreira, P. Almeida, L. D. Carlos and V. de Zea Bermudez, RSC Adv., 2012, 2, 2087-2099.

55. S. S. Nobre, P. P. Lima, R. A. S. Ferreira, R. O. Freire, L. Fu, U. Pischel, V. de Zea Bermudez, O. L. Malta and L. D. Carlos, J. Phys. Chem. C, 2007, 111, 3275-3284.

56. S. S. Nobre, C. D. S. Brites, R. A. S. Ferreira, V. de Zea Bermudez,

80 C. Carcel, J. J. E. Moreau, J. Rocha, M. Wong Chi Man and L. D. Carlos, J. Mater. Chem., 2008, 18, 4172-4182.

57. J. F. Nagle and M. Goldstein, Macromolecules, 1985, 18, 26432652.

58. P. E. Anderson, H. J. Jensen, L. P. Oliveira and P. Sibani, Complexity, 2004, 10, 49-56. 


\section{TOC}

\section{Fractality and metastability of a complex amide cross-linked dipodal alkyl/siloxane hybrid}

S. C. Nunes", C. B. Ferreira, R. A. S. Ferreira, L. D. Carlos, M. C. Ferro, J. F. Mano, P. Almeida, V. de Zea Bermudez

A complex metastable room temperature white light emitter non-bridged silsesquioxane exhibiting hierarchical structure, fractal crystallinity and a texture mimicking lettuce corals was produced by self-organization.

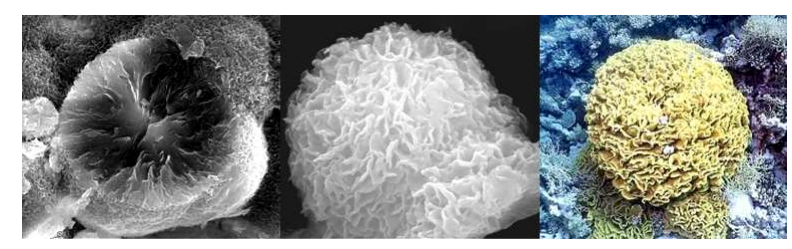

